\begin{tabular}{|c|c|c|c|}
\hline $\begin{array}{l}\text { Submission: } 24 / 11 / 2020 ; \\
\text { Camera ready: } 26 / 03 / 2021 \text {; }\end{array}$ & $\begin{array}{l}1^{\text {st }} \text { round notif.: } 30 / 12 / 2020 \text {; } \\
\text { Edition review: } 27 / 03 / 2021 \text {; }\end{array}$ & $\begin{array}{l}\text { New version: } 01 / 02 / 2021 ; \\
\text { Available online: } 03 / 04 / 2021 \text {; }\end{array}$ & $\begin{array}{l}2^{\text {nd }} \text { round notif.: } 28 / 02 / 2021 \text {; } \\
\text { Published: } 03 / 04 / 2021 ;\end{array}$ \\
\hline
\end{tabular}

\title{
Modelo de Avaliação Formativa para a Aprendizagem com Gamificação: Um Estudo de Caso para o Ensino de Engenharia
}

\author{
Title: Formative Assessment Model for the Learning with Gamification: A Case Study for \\ Engineering Teaching
}

\author{
Marcos Ceron Gonçalves \\ Universidade Federal do Rio \\ Grande \\ marcos.ceron89@gmail.com
}

\author{
André Luis Castro de Freitas \\ Universidade Federal do Rio \\ Grande \\ dmtalcf@furg.br
}

\author{
Eder Mateus Nunes Gonçalves \\ Universidade Federal do Rio \\ Grande \\ edergoncalves@furg.br
}

\begin{abstract}
Resumo
Este artigo apresenta um modelo de avaliação para a aprendizagem baseado em gamificação fundamentado no conceito de avaliação formativa, elaborado por meio da plataforma Moodle. Os relatos de estudos de caso relacionados demonstram que, ao se trabalhar com gamificação, a construção do processo avaliativo é problemática. A partir das concepções depreendidas da fundamentação teórica, foi idealizada a aplicação baseada no modelo proposto. Para a realização do estudo de caso, foram compostos dois grupos a partir de um total de onze estudantes de Engenharia de Computação da Universidade Federal do Rio Grande (FURG): grupo controle, que realizou as tarefas utilizando a forma padrão da disciplina; e grupo experimental, que utilizou o modelo elaborado nesta pesquisa. Os resultados foram obtidos sob duas perspectivas: qualitativa e quantitativa. A primeira analisou o desempenho dos estudantes nas tarefas comparando as pontuações alcançadas para cada um dos grupos. A segunda mensurou o impacto e a aceitação da ferramenta proposta como facilitadora da avaliação para a aprendizagem. Concluiu-se que os estudantes que utilizaram o modelo gamificado obtiveram melhores resultados em termos de notas, na comparação com o grupo de controle, bem como consideraram positiva a experiência com a ferramenta. Dessa forma, é possível inferir que o modelo de avaliação formativa gamificado contribui para a aprendizagem no contexto em que foi empregado.
\end{abstract}

Palavras-Chave: Gamificação; avaliação formativa; educação; engenharia; ambientes de aprendizagem.

\begin{abstract}
This paper presents an assessment model for the learning based on the formative assessment concept's gamification, created through the Moodle plataform. The related case studies demonstrate that, when working with gamification, the assessment process construction is problematic. From the theoretical foundation, an application was conceived based on the proposed model. In the case study carried out with the model, two groups were formed from a total of eleven Computer Engineering students from Federal University of Rio Grande (FURG): a control group, which performed the standard tasks of the discipline; and an experimental group that used the gamified assessment model developed in this research. The results were cataloged from two perspectives: qualitative and quantitative. The first one analyzed the scores achieved by each group. The second one measured the impact and acceptance of the tool as a learning assessment facilitator. The collected data allows concluding that the students who used the gamified formative assessment model obtained better results in terms of grades, in comparison with the control group, as well the students considering positive the experience with the tool. The gamified assessment model contributes to learning in the context in which it was applied.
\end{abstract}

Keywords: Gamification; formative assessment; education; engineering; learning environments.

Cite as: Gonçalves, M. C., Freitas, A. L. C., \& Gonçalves, E. M. N. (2021). Formative Assessment Model for the Learning with Gamification: A Case Study for Engineering Teaching (Modelo de Avaliação Formativa para a Aprendizagem com Gamificação: Um Estudo de Caso para o Ensino de Engenharia). Brazilian Journal of Computers in Education (Revista Brasileira de Informática na Educação - RBIE), 29, 358-384. DOI: $10.5753 /$ RBIE.2021.29.0.358 


\section{Introdução}

A constante busca por promover a motivação e o engajamento dos estudantes nas diversas modalidades acadêmicas trouxe a necessidade de inovações na área educacional. Deste cenário surge o conceito de gamificação. A origem do termo vem do inglês, "gamification", um neologismo baseado na palavra "game" (Kapp, 2012). Se fosse necessário traduzir conforme a língua culta, o resultado poderia ser algo como "joguificação". Considerando que a origem da palavra tem relação com os jogos eletrônicos (não exclusivamente, mas prioritária) e que no Brasil o termo "videogame" é aceito (ainda que em Portugal seja referido como "videojogo") a forma aportuguesada "gamificação" encontra respaldo na literatura. Segundo Kapp (2012), a gamificação consiste em utilizar elementos de jogos como estratégias, pensamentos e problematizações fora do contexto dos games.

A ideia de gamificação pode ser compreendida de acordo com o diagrama proposto por Deterding et al. (2011), que insere o conceito entre dois eixos, conforme pode ser visto na Figura 1. Segundo os autores, os jogos pressupõem uma estruturação com sistemas explícitos de regras e competições ou conflitos em direção a metas ou resultados predefinidos enquanto que a brincadeira é uma categoria ampla, livre e expressiva em relação aos jogos, ainda que exista nos mesmos a presença de elementos ou a caracterização como brincadeira. No diagrama, o eixo horizontal traz a noção de um jogo completo ou de suas partes (elementos) e o vertical vai da brincadeira (livre e descontraída) para o jogo (categórico na comparação com a brincadeira). Demonstra-se dessa forma que a gamificação utiliza elementos dos games, sem necessariamente trazer um jogo propriamente dito como resultado final e também se diferencia do design lúdico, visto que este pressupõe um aspecto de maior liberdade.

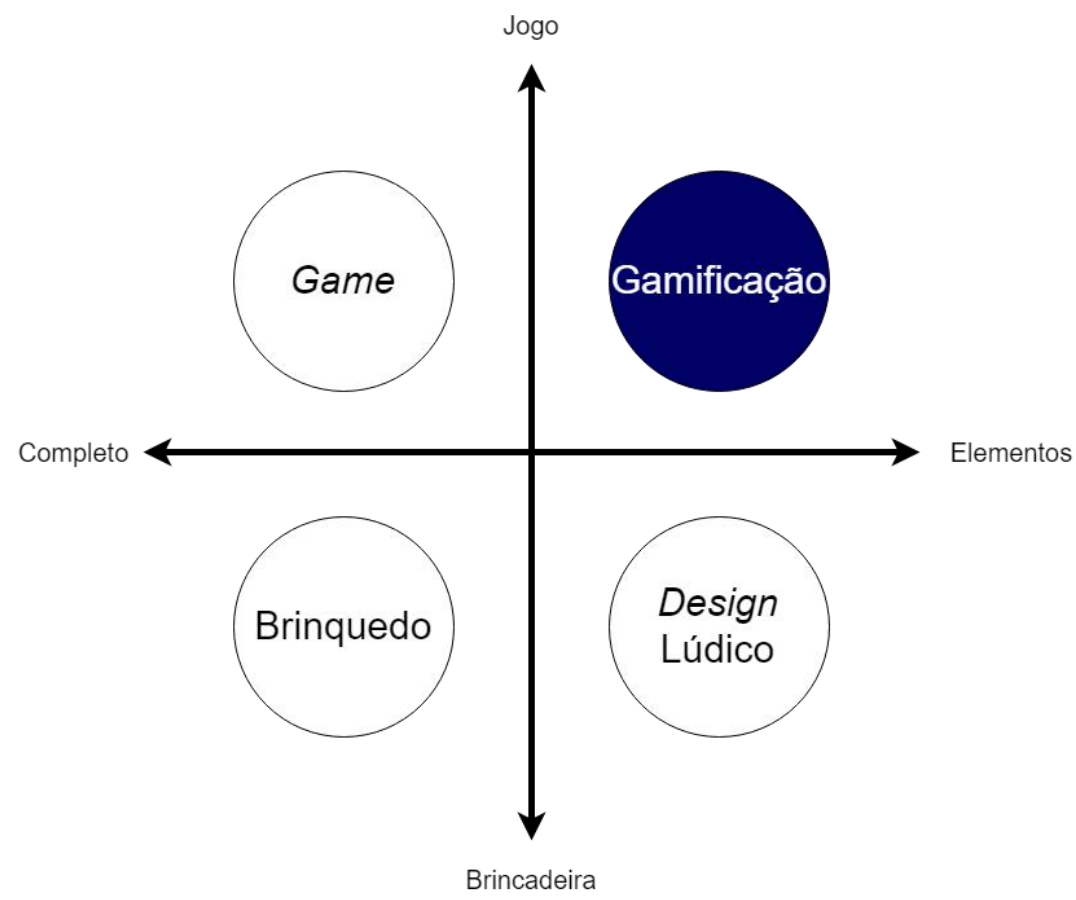

Figura 1: Contextualização da gamificação. Fonte: Adaptado de (Deterding et al., 2011).

De acordo com McGonigal (2012), existem quatro elementos que os jogos compartilham: Meta, Regras, Sistema de Feedback e Participação Voluntária. A ideia da gamificação é produzir um ambiente que aproveite tais características em um espaço fora do escopo de um jogo propriamente dito. A Tabela 1 apresenta a descrição de cada elemento. $\mathrm{O}$ 
recurso de gamificação feedback foi utilizado como base para o desenvolvimento do modelo proposto.

Tabela 1: Elementos de jogos. Adaptado de McGonigal (2012).

\begin{tabular}{|c|l|}
\hline Elemento & \multicolumn{1}{|c|}{ Descrição } \\
\hline Meta & O objetivo do jogo: resultado que os jogadores devem trabalhar para atingir. \\
\hline Regras & $\begin{array}{l}\text { Limitações das atividades possíveis de serem desenvolvidas pelo jogador na } \\
\text { exploração do jogo. }\end{array}$ \\
\hline Sistema de Feedback & $\begin{array}{l}\text { Retorno ao jogador sobre o seu desempenho em determinado momento em relação ao } \\
\text { objetivo a ser alcançado. Nesse contexto, podem ser inseridos sistemas de pontuação, } \\
\text { níveis, placares ou barras de progresso. }\end{array}$ \\
\hline $\begin{array}{c}\text { Participação } \\
\text { Voluntária }\end{array}$ & $\begin{array}{l}\text { A aceitação consciente e espontânea das características anteriores - Meta, Regras e } \\
\text { Feedback - forma a base para o funcionamento esperado dos jogos. }\end{array}$ \\
\hline
\end{tabular}

As técnicas gamificadas podem ser aplicadas em diferentes setores como o contexto empresarial (Salami et al., 2018), aplicações comerciais (Wünderlich et al., 2020), publicidade (Tobon et al., 2020) e educação (Fardo, 2013). Dentre eles, a gamificação em ambientes educacionais, tanto no âmbito presencial ou virtual, vem ganhando atenção de diferentes autores (McGonigal, 2012; Tolomei, 2017).

A aplicabilidade da gamificação voltada particularmente para as disciplinas e cursos de engenharia é registrada frequentemente em estudos de casos práticos. O emprego da técnica aparece nas seguintes formas (Ávila e Gómez, 2017; Boaventura e Oliveira, 2018):

- Inclusão de elementos típicos de jogos no Ambiente Virtual de Aprendizagem (AVA) da disciplina.

- Utilização de jogo existente como ferramenta de apoio.

- Adaptação de jogo existente para o propósito específico do curso ou disciplina.

As ferramentas de avaliação para a aprendizagem são também objeto de estudo que geram debates sobre a definição da avaliação em si, as dificuldades encontradas no processo, a contraposição entre a avaliação objetiva e subjetiva e os aspectos negativos que uma metodologia puramente classificatória pode acarretar (Bordernave, 1977; Ortigão et al., 2019; Machado, 1995; Mendes, 2005; Silva e Mendes, 2017). A partir dessas reflexões, percebe-se a necessidade de identificar o entendimento de uma avaliação que aconteça de forma contínua e que acompanhe todo o processo de construção da aprendizagem, prática que ficou definida como o conceito de avaliação formativa (Casanova et al., 2017; Mendes, 2005; Santos et al., 2021).

A análise de publicações relacionadas permite considerar que a disponibilização de diferentes caminhos para um objetivo, mecanismo de feedback, dificuldade gradativa, divisão das tarefas complexas em etapas menores, inclusão do erro como processo de aprendizagem, narrativa, competição, colaboração e, por fim, levar em conta a diversão no processo de aprendizagem sejam apontados como aspectos positivos da aplicação da gamificação (Fardo, 2013; Klock et al., 2014; Santos et al., 2021; Tolomei, 2017). Por outro lado, o fato de prender o professor ao recurso e dar a ideia de que os estudantes só devem estudar quando recebem recompensas são citados como fatores negativos (Lee e Hammer, 2011).

Tendo como base as considerações apresentadas, este artigo apresenta o modelo desenvolvido para o processo de avaliação formativa para a aprendizagem utilizando técnicas de gamificação, com o objetivo de propor uma ferramenta de avaliação alternativa às tradicionalmente utilizadas em estratégias gamificadas. $\mathrm{O}$ modelo foi experimentado com voluntários em turma de Engenharia de Computação da Universidade Federal do Rio Grande (FURG), então divididos em dois grupos: um foi avaliado por meio do ambiente gamificado e 
outro executou uma tarefa comum da disciplina. Por fim, foram catalogados os resultados obtidos com a realização do estudo de caso, em que o aspecto quantitativo comparou o desempenho dos estudantes de cada grupo e o qualitativo mediu a repercussão da aplicação da ferramenta no sentido de fomentar a avaliação para a aprendizagem.

\section{Trabalhos Relacionados}

As publicações encontradas em pesquisas relacionadas ao tema do presente artigo apontam uma deficiência na análise específica dos métodos de avaliação dos estudantes em ambientes educacionais gamificados. A maioria dos estudos concentra seus esforços em demonstrar a aplicação da gamificação na disciplina ou em uma parte dela, com o objetivo de impulsionar o engajamento dos estudantes, substituindo ou incrementando as aulas expositivas, como pode ser observado nas publicações de Piteira et al. (2017), Barata et al. (2013) e Evangelista et al. (2018). Em geral, a prática avaliativa não é o destaque principal nos estudos que demonstram técnicas gamificadas que possibilitam essa finalidade, sendo comum encontrar exemplos de experiências educacionais baseadas em elementos de jogos nas quais a avaliação foi feita nos moldes tradicionais (Evangelista et al., 2018). Assim sendo, foi realizada uma revisão bibliográfica direcionada a identificar os métodos utilizados na literatura para avaliar os estudantes em contextos educacionais que apliquem a gamificação.

Silva et al. (2019) apresentam uma experiência de gamificação em disciplinas de informática de turmas de ensino médio e técnico integrado. Foi feito um comparativo entre a disciplina utilizando gamificação no conteúdo com avaliação tradicional e, posteriormente, conteúdo e avaliação gamificados. Os elementos utilizados para a avaliação foram: pontos de experiência, nível (nesse caso níveis alcançáveis pelos estudantes, de acordo com sua pontuação), ranking e conquistas. Os autores concluíram, por meio da investigação com questionários, que a estratégia trouxe benefícios no que se refere ao desempenho dos estudantes, velocidade do feedback nas avaliações e autonomia para realização das atividades.

A publicação de Attali e Arieli-Attali (2015) analisa o impacto de um elemento específico de gamificação voltado para a avaliação para a aprendizagem: a pontuação. Foram realizados testes por meio de um sistema de avaliação de perguntas e respostas. A experiência ocorreu em dois estudos separados com grupos distintos: um com adultos e outro com estudantes de ensino fundamental. A velocidade da resposta era analisada nestes experimentos, sendo tão importante quanto a sua precisão, com o objetivo de analisar o domínio e a fluência dos conceitos básicos de matemática. A aplicação de pontos, segundo os autores, apresentou efeitos secundários tanto para os adultos quanto para os jovens estudantes. Houve incremento de desempenho no que diz respeito à velocidade de resposta, porém não se demonstrou impacto no quesito precisão.

No estudo de Fardo (2013) é proposta a identificação do conceito da gamificação no contexto educacional, conforme a compilação de dados encontrados na literatura, e são traçadas linhas gerais para a utilização da metodologia para avaliação para a aprendizagem, quais sejam: disponibilização de diferentes caminhos para um objetivo, mecanismo de feedback, dificuldade gradativa, divisão das tarefas complexas em etapas menores, inclusão do erro como processo de aprendizagem, narrativa, competição, colaboração e, por fim, levar em conta a diversão no processo de aprendizagem.

É apresentada, na publicação de Menezes e Bortoli (2016), uma pesquisa sobre possibilidades de aplicação de técnicas gamificadas. Há destaque para a importância do feedback e as maneiras pelas quais a gamificação pode oferecer esse recurso de forma imediata. 
Outro ponto mencionado é a possibilidade de re-playing ("jogar novamente" ou tentativas), no qual o estudante pode retomar o "percurso" de determinado ponto, em caso de erro.

Seaborn e Fels (2015) demonstram, em sua pesquisa sistemática, a análise de estudos conceituais e práticos a respeito da gamificação em diversas categorias: comunidades online e redes sociais, saúde e bem estar, crowdsourcing (colaboração coletiva), sustentabilidade e orientação, além da área educacional. Os autores afirmam que é questionável a abordagem gamificada baseada exclusivamente nos elementos de pontuação, distintivos e quadros de liderança (rankings), argumentando que essa metodologia poderia ser chamada de pointsification ("pontificação"), ao invés de gamificação.

Na publicação de Toda et al. (2017) é apresentado um estudo com elementos de gamificação para o uso de plataformas de Recursos Educacionais Abertos (REAs). Entre os elementos que trabalham a avaliação dos estudantes incluídos estão o sistema de pontuação, o placar de liderança e as conquistas. A pontuação foi aplicada por meio de um sistema de tokens que atribuía pontos de acordo com as ações desenvolvidas pelos usuários. O placar foi apresentado em um ambiente competitivo no qual o usuário podia comparar seus resultados e as conquistas consistiram na concessão de emblemas de acordo com o desempenho do usuário em determinado evento.

O estudo de Vieira et al. (2019) apresenta uma pesquisa bibliográfica que analisa as práticas de gamificação no ensino superior procurando por estudos que descrevessem uma experiência prática com participantes. Os autores listam estratégias para aplicação da técnica, nas quais sistemas de pontuação, rankings e medalhas são citados como elementos de avaliação viáveis.

Com a análise do conteúdo das publicações, a ocorrência dos seguintes elementos de avaliação em sistemas educacionais gamificados foi identificada: quadro de rankings (Silva et al., 2019), sistema de pontuação (Rojas e Fraser, 2016), sistema de recompensas (medalhas) (Brazil e Baruque, 2015) e feedback (Menezes e Bortoli, 2016). A simples aplicação desses elementos para avaliação é criticada, uma vez que, se empregados de forma trivial, podem não trazer o resultado esperado (Brazil e Baruque, 2015; Seaborn e Fels, 2015; Vieira et al., 2019).

"Frequentemente, como esforço de imitar as características motivacionais de jogos, a gamificação reduz a complexidade aos seus mais simples componentes, a meramente pontos, tabelas classificatórias e conquistas." (Vieira et al., 2019, p. 16).

Além disso, a utilização de tabelas de posição de acordo com os pontos obtidos é considerada problemática, uma vez que a avaliação por ranking acarreta na exposição do nome do estudante enquanto que, no modelo tradicional de avaliação, o resultado de uma prova é individualizado e, na maioria das vezes, restrito ao professor (Cavalcante et al., 2018; Sande e Sande, 2018).

A gamificação é encontrada na aplicação de técnicas para desenvolver algum conteúdo específico (Rojas e Fraser, 2016) ou como metodologia para impulsionar o engajamento dos estudantes na disciplina (Silva et al., 2019), ou parte dela (Brazil e Baruque, 2015). Não se encontra, entre os estudos elencados, a preocupação em analisar a gamificação voltada especificamente para a avaliação dos estudantes. Existem exemplos em que são empregados elementos baseados em jogos para a exposição do conteúdo, mas a avaliação continua sendo realizada da maneira tradicional (Evangelista et al., 2018). Quando são aplicados elementos avaliativos, os mesmos correspondem a uma porcentagem do valor total da nota ou são utilizados no contexto específico em que a gamificação foi aplicada, considerado o caráter 
voluntário que a aplicação da técnica costuma apresentar (Cavalcante et al., 2018; McGonigal, 2012; Sande \& Sande, 2018).

A partir dos conceitos elencados, o presente artigo apresenta o modelo constituído com o propósito de trabalhar a gamificação voltada para a avaliação, em sua perspectiva formativa, aplicado a uma turma de engenharia. Espera-se, com isso, contribuir para preencher a lacuna identificada na literatura, no que se refere a estudos que tenham seu foco principal na questão da avaliação formativa para aprendizagem utilizando gamificação.

\section{Fundamentação Teórica}

Definir um conceito para avaliação é uma tarefa complexa e seu significado é um assunto que gera debates entre diversos autores (Araújo e Diniz, 2015; Cunha, 1999; Harlen e James, 1997; Kenski, 1994; Luz, 1997). Embora a motivação de se avaliar seja clara, ou seja, analisar e certificar se os conteúdos expostos nas aulas foram satisfatoriamente aprendidos, bem como constatar as habilidades e competências trabalhadas, a definição do processo de avaliação e as maneiras possíveis para realizá-lo, entre outras questões, merecem uma reflexão mais profunda (Luz, 1997).

Como forma de elucidar as diversas concepções acerca do tema, Dias Sobrinho e Balzan (1995) argumentam o seguinte:

"A avaliação implica um fundamentado conhecimento daquilo que interrogamos $e$ atribuição de significados aos fatos, dados e informações que colhemos. Para além dos fatos e a partir deles, a produção dos juízos de valor. Avaliar é uma ação que não admite neutralidade. Ultrapassa as descrições objetivas e as análises de coerência interna da realidade tomada por objeto. É um processo de forte conteúdo ético, pois indaga valores e significados sociais.” (p. 72)

Ao retomar a ideia da ética inerente ao processo de avaliação, fica clara, na visão dos autores, a existência de considerações a serem ponderadas, que vão além do mero procedimento técnico de atribuir uma nota ou conceito ao estudante. A prática rotineira de aplicar a atividade de avaliação, corrigir e entregar o resultado, não é, segundo Luckesi (1998), um procedimento avaliativo, mas uma mera verificação dos resultados obtidos pelos estudantes. A verificação não implica que o sujeito retire consequências novas e significativas, uma vez que os erros não são aproveitados para rever o trabalho, rediscutir o conteúdo dado e modificar a realidade verificada. A aplicação da prova nos moldes tradicionais acaba servindo apenas para classificar o estudante e não para diagnosticar a realidade avaliada (Mendes, 2005; Santos et al., 2021; Silva et al., 2020).

Bordernave (1977) argumenta sobre a determinação dos aspectos qualitativos e quantitativos do comportamento do estudante por parte do professor, alegando que essa determinação apresenta duas funções principais: (a) acompanhar o processo de aprendizagem, diagnosticando-a e controlando-a e (b) selecionar e classificar estudantes para a aprendizagem.

É possível correlacionar os problemas encontrados na definição teórica do conceito do processo avaliativo educacional como um todo e os debates acerca das distorções encontradas em avaliações utilizando técnicas gamificadas. A avaliação classificatória, que pode ser observada no emprego dos rankings gamificados, já era identificada como um problema no processo avaliativo tradicional da educação por Cunha (1999) e Luz (1997). O paradigma de avaliação de orientação técnica traz a ideia do uso de "rankings" e de indicadores qualitativos (Cunha, 1999). Nesse sentido, Dias Sobrinho e Balzan (1995) alegam que o modelo de avaliação na ótica eficientista, instrumentalista e classificatória é predominantemente quantitativo. 
Segundo os autores, a quantificação é um primeiro passo em alguns casos, e conforme os objetivos, fundamental e imprescindível à avaliação, mas não suprime a necessidade imperiosa de todos os outros enfoques e procedimentos. Não é recomendável a avaliação baseada na competição, bem como é considerada prejudicial a comparação dos resultados obtidos pelos estudantes entre si (Mendes, 2005; Silva et al., 2020).

"As concepções de avaliação emitidas por professores universitários ainda envolvem, fundamentalmente, pontos como avaliar para a competitividade, com ênfase na memorização de conteúdos e na desvalorização de mecanismos de avaliação diferentes das tradicionais provas." (Ludke e Salles, 1997, p. 174)

\subsection{Avaliação Formativa}

Diante dos problemas que os métodos tradicionais quantitativos apresentam e considerando o fato de que o objetivo de avaliar o estudante é diagnosticar sua evolução no processo de aprendizado e não a sua classificação (Luz, 1997; Santos e Kroeff, 2018), vê-se a necessidade de novas metodologias de avaliação. Manifestou-se, portanto, a tendência de encarar $o$ conhecimento como processo em oposição à perspectiva tradicional de considerá-lo um produto (Casanova et al., 2017). O conhecimento demanda, mais do que armazenagem, capacidade de interpretação e ressignificação (Cunha, 1999). Kenski (1994) argumenta que a avaliação ocorre durante todo o processo de ensino, nas relações dinâmicas de sala de aula e deve orientar as tomadas de decisão frente ao conhecimento.

"A avaliação para a aprendizagem adquire seu sentido na medida em que se articula com um projeto pedagógico e com seu consequente projeto de ensino. A avaliação, tanto no geral quanto no específico da aprendizagem, não possui uma finalidade em si; ela subsidia um curso de ação que visa construir um resultado previamente definido." (Luckesi, 1998, p. 85)

O que se deseja é um estudante capaz de pensar, de transitar nas ideias, de interpretar a informação disponível, de construir alternativas, de dominar processos que levem a novas investigações, de desenvolver o espírito crítico e tantas outras habilidades extremamente necessárias. No mesmo sentido, surge a necessidade de trabalhar o ensino com a lógica da pesquisa, no qual há a preocupação com o processo de produção do conhecimento em que as dúvidas são encorajadas (Cunha, 1999).

A partir da análise das situações mencionadas, surgiu o conceito de avaliação formativa. De acordo com Mendes (2005), avaliação formativa é toda prática de avaliação contínua que pretenda contribuir para melhorar as aprendizagens em curso, qualquer que seja o quadro e qualquer que seja a extensão concreta da diferenciação do ensino. O objetivo é identificar uma metodologia avaliativa que, ao valorizar todo o processo de construção da aprendizagem, dissipe as distorções encontradas no modelo tradicional. Nesse sentido, as tradicionais provas não seriam totalmente descartadas, mas fariam parte do sistema avaliativo, sem necessariamente ocupar o papel de maior destaque (Casanova et al., 2017; Cunha, 1999). O objetivo da avaliação formativa é dar a oportunidade ao estudante de tomar consciência das suas dificuldades, para assim perceber os seus erros e corrigi-los (Silva et al., 2020).

A ideia de uma metodologia educacional baseada em elementos de jogos tem a capacidade de contribuir para a aplicação dos conceitos de avaliação formativa. Três elementos de gamificação destacam-se por estarem alinhados aos paradigmas formativos: (a) o feedback imediato; (b) a valorização do erro como motivador da aprendizagem, por meio de novas tentativas e (c) a utilização de diferentes "caminhos" para atingir o mesmo objetivo. 
"Se o aluno não aprendeu de uma forma, é preciso tentar outras formas até que ele aprenda. Para isso precisamos ter coragem de atrasar o programa e atender às necessidades de nossos alunos. Isso quer dizer que precisamos retomar, rever, reenfocar, replanejar, alterar o ritmo buscar novas estratégias de abordagem." (Mendes, 2005, p. 6)

Abreu e Masetto (1989) afirmam que a avaliação como processo permite desvios e sua correção. Os autores citam o feedback constante, um pilar da gamificação, como um dos elementos que permitem uma visão de conjunto sobre avaliação. O feedback contínuo deve estar alinhado ao processo de avaliação, sendo elemento central para a aprendizagem dos estudantes (Casanova et al., 2017). Na mesma linha, Silva e Mendes (2017) afirmam que o feedback é o elemento-chave da avaliação formativa.

A perspectiva formativa de avaliação deve ocorrer por meio de um processo contínuo, de acordo com uma organização do ensino-aprendizagem, de maneira conjunta e colaborativa, promovendo a cooperação entre professores e alunos (Casanova et al., 2017; Santos et al., 2021). A disponibilização do retorno contínuo e personalizado ao estudante, de acordo com o seu desempenho, proporciona a articulação entre a coleta de informações e a ação necessária para a obtenção do objetivo almejado no processo de avaliação para a aprendizagem (Santos et al., 2021; Silva et al., 2020).

Diante dos conceitos apresentados, surgiu a necessidade de construir um modelo avaliativo que não seja definitivo em punir os erros, permitindo um reiniciar contínuo, utilizando um mecanismo de feedback que possibilite ao estudante a abertura de novas tentativas até atingir os objetivos iniciais propostos. A gamificação pode contribuir para o processo de avaliação educacional que pretenda seguir nessa direção, utilizando elementos que favoreçam esse tipo de abordagem, em contraposição aos tradicionais métodos gamificados de classificação e comparação.

\section{Modelo de Avaliação Formativa com Gamificação}

A partir da problematização exposta na Seção 3, foi concebido um modelo de avaliação formativa integrado à ideia de aprendizado baseado em gamificação. Os conceitos extraídos da fundamentação teórica balizaram a construção do modelo. O mecanismo de feedback traz a ideia de apresentar respostas ao estudante de acordo com o seu desempenho em determinado tempo, sendo, portanto, favorável aos objetivos aqui propostos. Por outro lado, as técnicas típicas de avaliação gamificada, como rankings de pontuação, foram substituídas, uma vez que o estímulo à competitividade não é uma característica que se alinhe ao método de avaliação formativa. (Cunha, 1999; Luz, 1997)

A elaboração do modelo foi baseada no conceito de tarefas sequenciais com aumento gradativo de dificuldade, oferecendo retorno imediato ao estudante, bem como a possibilidade de caminhos alternativos para a obtenção de um objetivo predefinido. O elemento de gamificação que atende a esses preceitos é o dos Níveis ou Fases. Os níveis gamificados podem ser entendidos como atividades sequenciais, com dificuldade e complexidade graduais, concepção utilizada neste estudo, bem como níveis de experiência, ou seja, graus de desempenho predeterminados que os estudantes podem alcançar, de acordo com seu aproveitamento nas atividades, medidos conforme a sua pontuação (Silva et al., 2019). Neste artigo, será adotada a nomenclatura "Fases" para as tarefas sequenciais e "níveis de interação" para o conjunto composto de cada fase com seus materiais de apoio e tentativas extras. 
O projeto estabeleceu que o estudante deve ter acesso a uma fase inicial no formato de um questionário e avançar gradativamente para tarefas de maior complexidade, caso atinja o objetivo proposto na etapa anterior. Não havendo êxito na atividade, o ambiente oferta opções de recursos didáticos de apoio em formatos como texto, gráficos ou vídeos, para então possibilitar uma nova tentativa de atividade ao estudante, com o mesmo nível e complexidade.

O mecanismo de feedback é utilizado para promover a interação com o estudante de acordo com o seu progresso no determinado momento. Espera-se, dessa forma, atender aos pilares da avaliação formativa que falam sobre um curso de ação dinâmico para atingir uma meta predefinida (Kenski, 1994; Luckesi, 1998; Mendes, 2005). A concepção de curso de ação dinâmico é identificada na fala de Mendes (2005), que defende a ideia de oferecer novas tentativas ao estudante caso o aprendizado não tenha sido alcançado. $O$ conceito tem relação com o argumento de Luckesi (1998), quando propõe a avaliação como um processo que promova atividades considerando as particularidades de cada estudante, visando construir um objetivo predefinido. Na mesma linha, Kenski (1994) menciona que a avaliação deve ocorrer durante todo o processo de aprendizagem, atentando às relações dinâmicas de sala de aula. $\mathrm{O}$ curso de ação dinâmico é representado neste projeto pelos níveis de interação com tarefas alternativas e materiais didáticos de apoio. A Figura 2 mostra o fluxograma do modelo proposto.

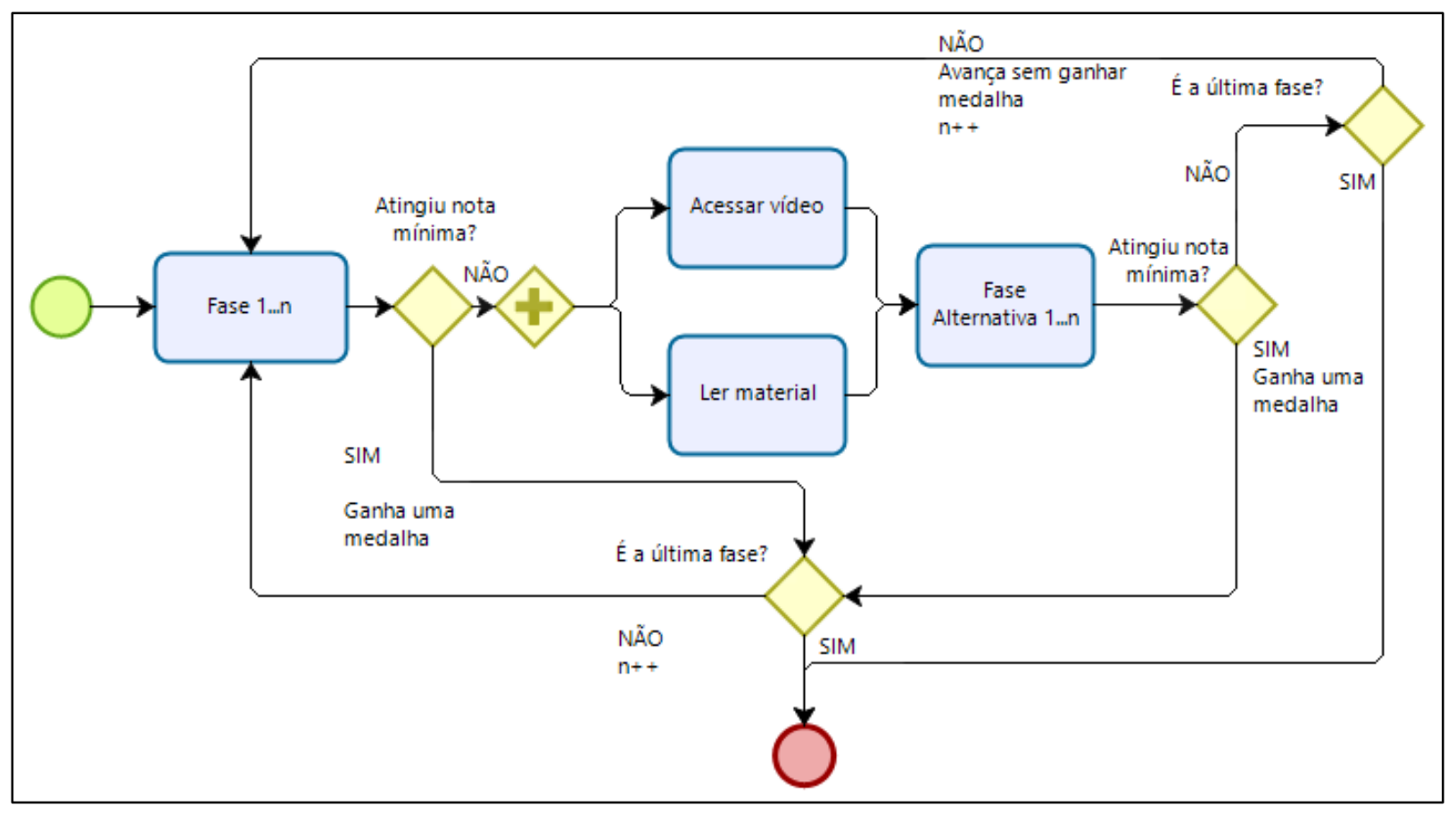

Figura 2: Fluxograma do modelo. Fonte: autor.

No acesso inicial ao ambiente, a primeira fase é a única visível para o estudante. Caso atinja a pontuação mínima exigida naquela tarefa, ganha uma medalha e recebe o retorno do sistema que, em seguida, verifica se existem mais fases disponíveis. Em caso afirmativo, a próxima fase é apresentada. Se não obtiver sucesso, o estudante recebe o feedback correspondente e são disponibilizados materiais de apoio no formato de vídeo ou texto. $\mathrm{O}$ participante deve acessar pelo menos uma das opções para assim habilitar a fase alternativa, que tem funcionamento igual ao da fase regular, contando com questões diferentes acerca do mesmo assunto, com o mesmo nível de dificuldade. Se passar da fase alternativa, o estudante ganha recompensa no formato de medalha; caso contrário, avança sem gratificação. O objetivo é oferecer caminhos alternativos sem, contudo, privar o estudante de tentar cumprir o desafio por inteiro, por isso ele não é eliminado se não passar de fase. Dessa forma, espera-se atender aos princípios da avaliação formativa que defendem a valorização dos erros ao invés da aplicação de punições em decorrência dos mesmos (Cunha, 1999; Mendes, 2005). O sistema verifica a 
existência de mais fases cada vez que o estudante termina uma tarefa, seja no fluxo regular ou alternativo. Caso o questionário que o estudante concluiu no dado momento corresponda à última fase, a atividade é encerrada.

A ideia foi combinar os conceitos de avaliação formativa com as técnicas de gamificação. A intenção planejada ao apresentar uma ferramenta de tarefas interativas, em que o estudante tem acesso a materiais de apoio em caso de erro e, a partir disso, a possibilidade de refazer a atividade foi a de estar alinhado com o conceito de avaliação formativa percebido na afirmação de Luckesi (1998), quando argumenta que a avaliação deve subsidiar um curso de ação visando construir um resultado previamente definido. No projeto aqui descrito, o objetivo final consiste no estudante percorrer as quatro atividades avaliativas concebidas mediante o elemento de gamificação Fases e o curso de ação dinâmico está relacionado aos níveis de interação com tentativas extras e acesso a conteúdos didáticos.

A interação entre as tarefas com mensagens do Avatar está relacionada ao conceito de feedback constante defendido por Abreu e Masetto (1989), bem como a ideia de não punir os erros, mas utilizá-los como ferramenta motivadora para novas aprendizagens, ao proporcionar o fluxo de tarefas com tentativas extras, é um elemento de avaliação formativa que encontra respaldo nos discursos de Cunha (1999), Mendes (2005) e de Abreu e Masetto (1989).

Harlen e James (1997) enumeram as seguintes características da avaliação plena formativa:

- Destina-se a promover a aprendizagem;

- Leva em conta o progresso individual, o esforço nele colocado e outros aspectos não especificados no currículo. Em outras palavras, não é inteiramente baseado em critérios;

- Capacidades e ideias que, na avaliação tradicional, poderiam ser classificadas como "erros" fornecem informações diagnósticas;

- Os estudantes exercem papel central, devendo atuar ativamente em sua própria aprendizagem; eles progredirão se compreenderem suas possibilidades e fragilidades e se souberem como se relacionar com elas.

O modelo desenvolvido está associado às características de avaliação formativa encontradas na fala de Harlen e James (1997), uma vez que os níveis de interação destinam-se a promover a aprendizagem atribuindo aos estudantes o papel central no processo. O modelo foi concebido para levar em conta o progresso individual, de forma que cada estudante tenha diversas possibilidades de caminhos para atingir o objetivo planejado. As interações e tentativas extras valorizam a ideia de aproveitar os erros como ferramentas para obter informações, a fim de fomentar a busca por novos conhecimentos. A dinâmica das fases leva em conta o progresso individual de cada estudante, sem tecer comparações, uma vez que os participantes não têm acesso ao desempenho dos colegas.

O projeto considerou, também, os aspectos considerados prejudiciais da gamificação voltada para a avaliação. A avaliação classificatória e a comparação de resultados são consideradas prejudiciais ao processo de avaliação para a aprendizagem (Cavalcante et al., 2018; Cunha, 1999; Luz, 1997; Mendes, 2005). A partir dessa análise, foi tomada a decisão de não utilizar, no modelo proposto, os elementos de gamificação dos rankings classificatórios e sistemas de pontuação comparativos.

O elemento Medalhas (Badges) está associado à avaliação classificatória e ao mecanismo de recompensas (Brazil e Baruque, 2015; Vieira et al., 2019), além de potencialmente incutir a ideia de que os estudantes só devem realizar tarefas quando recebem recompensas (Lee e Hammer, 2011). A oferta de recompensas de acordo com o desempenho do estudante para comparação competitiva com os demais participantes não foi empregada neste 
modelo. O elemento Medalhas foi utilizado como marcador de progresso individual e com visualização restrita apenas ao participante em questão, contrapondo a aquisição de recompensa como objetivo central da atividade.

A ideia não foi conceber um modelo definitivo, mas aliar os conceitos de avaliação formativa com as técnicas de gamificação para a elaboração de uma ferramenta avaliativa, a fim de utilizá-la no estudo de caso em uma turma de engenharia, pretendendo, com isso, propor uma alternativa ao modo tradicional de se trabalhar a avaliação em projetos que utilizam a estratégia gamificada para a educação.

\section{Métodos e Procedimentos}

O modelo descrito na Seção 4 foi aplicado a um grupo de voluntários, em turma de Engenharia de Computação da FURG, com o objetivo de verificar o impacto das técnicas de gamificação incluídas na plataforma para a avaliação formativa para a aprendizagem, bem como para mensurar se a utilização do modelo atende às carências de ferramentas voltadas para essa finalidade, vislumbrada na fundamentação teórica. Para isso, a turma foi dividida em dois grupos, assim especificados:

- Grupo Controle: O grupo que não utilizou o modelo proposto. Esse grupo teve acesso a um questionário único que reuniu as quatro fases "regulares" de uma só vez, sem qualquer interação gamificada na plataforma.

- Grupo Experimental: O grupo que utilizou o modelo proposto. Esse grupo acessou o modelo desenvolvido com técnicas de gamificação descrito na Seção 4.

Para o grupo experimental foram disponibilizados dois conjuntos de quatro tarefas no formato de questionário interativo, cada um contendo três questões, com nível de dificuldade gradativo. O primeiro conjunto corresponde às tarefas que aparecem aos estudantes nas tentativas regulares e o segundo compreende as alternativas extras do modelo gamificado. As questões foram da categoria múltipla escolha, com quatro alternativas, sendo uma delas a correta. O grupo controle, por sua vez, teve acesso a um questionário único, sem uso de elementos de gamificação, no qual as questões do primeiro conjunto de tarefas apresentadas ao grupo experimental foram reunidas.

Para que a análise dos efeitos da aplicação do estudo de caso fosse a mais neutra possível, a divisão da turma de voluntários foi concebida de forma que a distribuição dos estudantes fosse equilibrada. Sendo assim, foi elencada uma lista de critérios baseados naqueles encontrados nas relações de aprovação do Sistema de Seleção Unificada (SISU), utilizado para promover o ingresso nas universidades no Brasil: gênero autodeclarado (facultativo), renda familiar bruta per capta em relação (superior ou igual/inferior) a 1,5 salário mínimo, ensino médio cursado integralmente em escolas públicas, etnia autodeclarada (facultativo) e deficiência.

Foi feito um levantamento, durante a aula da disciplina de Projeto e Desenvolvimento de Software I, de oferta anual no curso de Engenharia de Computação da FURG, a fim de angariar voluntários para participação no estudo. $\mathrm{O}$ total de estudantes interessados foi de 12 que foram, em seguida, divididos em dois grupos de seis. Cabe observar que todos os voluntários que se dispuseram a participar da atividade são do gênero masculino. Uma vez que do total de 24 estudantes frequentes, a turma contava com duas estudantes do sexo feminino, logo, a amostra está dentro do padrão estatístico esperado.

Ao reunir os dados dos estudantes, foi possível identificar que dentre os 12 voluntários nenhum é Portador de Necessidades Especiais (PNE), quatro cursaram o Ensino Médio integralmente em escola pública, oito se autodeclaram brancos e quatro detêm renda familiar 
inferior ou igual a 1,5 salário mínimo. No dia da atividade, um dos estudantes não compareceu, o que acarretou a diminuição do número total de componentes do grupo experimental para cinco. $\mathrm{O}$ perfil do estudante que não participou é: renda familiar menor do que 1,5 salário mínimo, não cursou o ensino médio integralmente em escola pública, autodeclarado pardo. A Tabela 2 apresenta o resultado final da divisão da turma, de acordo com cada um dos critérios:

Tabela 2. Divisão da turma.

\begin{tabular}{|c|ll|ll|ll|ll|}
\hline Critério & \multicolumn{3}{|c|}{ Grupo Experimental - Total: 5 } & \multicolumn{3}{c|}{ Grupo Controle - Total: 6} \\
\hline Gênero & Masculino: & 5 & Feminino: & 0 & Masculino: & 6 & Feminino: & 0 \\
\hline Renda (SM)* & Maior: & 3 & Menor/igual: & 2 & Maior: & 4 & Menor/igual: & 2 \\
\hline Ensino Médio & EP**: & 4 & Não: & 1 & EP**: & 4 & Não: & 2 \\
\hline Etnia & Brancos: & 4 & Outros: & 1 & Brancos: & 4 & Outros: & 2 \\
\hline PNE & Não: & 5 & Sim: & 0 & Não: & 6 & Sim: & 0 \\
\hline
\end{tabular}

* - Renda em relação a 1,5 salário mínimo.

** - Cursou o Ensino Médio integralmente em escola pública.

Com a divisão construída, no dia da atividade foi feita a separação dos estudantes nas bancadas do laboratório no horário de aula da disciplina de acordo com os grupos, a fim de evitar que houvesse colaboração entre os participantes de tarefas distintas. O grupo experimental realizou a atividade no modelo gamificado e o grupo controle respondeu ao questionário simples.

A fim de mensurar impacto da aplicação da ferramenta foram utilizados os relatórios de atividade fornecidos pelo ambiente Moodle, que permitem verificar as interações dos estudantes pelos recursos oferecidos no ambiente, por visualização, tempo de acesso e desempenho nas tarefas. A pesquisa de Rohling (2014) respalda a obtenção de informações via dados coletados pelos relatórios do AVA. A coleta das impressões dos estudantes acerca do modelo de avaliação apresentado no estudo de caso foi feita por meio do recurso da entrevista (Ferraro, 2012). Assim que encerraram sua participação no estudo, os estudantes foram convocados a responder um formulário interativo com questões de múltipla escolha e descritivas, para avaliar a ferramenta. Essa abordagem considerou, também, a argumentação de Bogdan e Biklen (1994), que defendem os aspectos interpretativos e descritivos da análise qualitativa, na qual o investigador deve interpretar os dados obtidos dos participantes e retirar as conclusões, sem se preocupar em arranjá-los para provar ou rejeitar hipóteses.

\subsection{Mecanismo de Funcionamento}

Para a realização do estudo de caso foi utilizado o AVA Moodle. Considerando que o objetivo foi propor uma tarefa avaliativa utilizando gamificação e não gamificar o conteúdo de uma disciplina, a ferramenta partiu diretamente para a atividade prática, por meio do recurso Questionário, com perguntas de múltipla escolha que permitem a correção automática. Foi criado um curso no Moodle para abrigar os conteúdos elaborados, que foi chamado de "Banco de Dados Gamificado".

Os elementos de gamificação utilizados foram: Narrativa, Regras, Avatar, Níveis ou Fases, Medalhas e Conquistas, Feedback e Barra de Progresso. As publicações de Tolomei (2017), Bissolotti et al. (2014), Klock et al. (2014) e de Santos e Freitas (2017) identificam elementos de gamificação utilizados em ambientes de ensino. Dentre os recursos mapeados, cabe destacar os seguintes: a Narrativa, que consiste na elaboração ou no uso de uma história para criar um ambiente com características imersivas, a fim de engajar o estudante. O sistema de Regras prevê a limitação da atividade do estudante dentro do ambiente gamificado para atingir um objetivo predefinido. Os Níveis ou Fases são subdivisões das tarefas do modelo gamificado em sequência, normalmente com nível de dificuldade crescente. Medalhas são recompensas 
dentro do escopo da gamificação oferecidas ao estudante por atingir determinadas Conquistas, que são resultados específicos a serem alcançados nas tarefas disponibilizadas no ambiente. $\mathrm{O}$ Feedback consiste no retorno ao estudante em relação ao seu desempenho nas tarefas e pode estar relacionado à Narrativa, quando o retorno faz parte da história. O elemento Avatar permite a representação gráfica de personagens e pode, também, estar ligado ao feedback e à narrativa, caso faça parte da história. Por sua vez, a Barra de Progresso é uma ferramenta que demonstra o ponto em que ponto o estudante se encontra em determinado tempo, no contexto das atividades em um sistema gamificado (Bissolotti et al., 2014; Klock et al., 2014; Santos e Freitas, 2017; Tolomei, 2017).

A visão inicial do estudante ao fazer $\operatorname{login}$ e acessar o curso exibe o Avatar do personagem que serviu de guia durante a experiência junto à listagem das regras da prática proposta e, abaixo, o questionário referente à primeira fase do modelo gamificado, o único conteúdo que aparece liberado ao primeiro acesso, sem restrições de conclusão. A Figura 3 mostra o que o estudante enxerga ao entrar no ambiente pela primeira vez. A narrativa presente está ligada à apresentação das regras pelo avatar, feedbacks personalizados de acordo com o desempenho do estudante e à liberação dos elementos de gratificação.

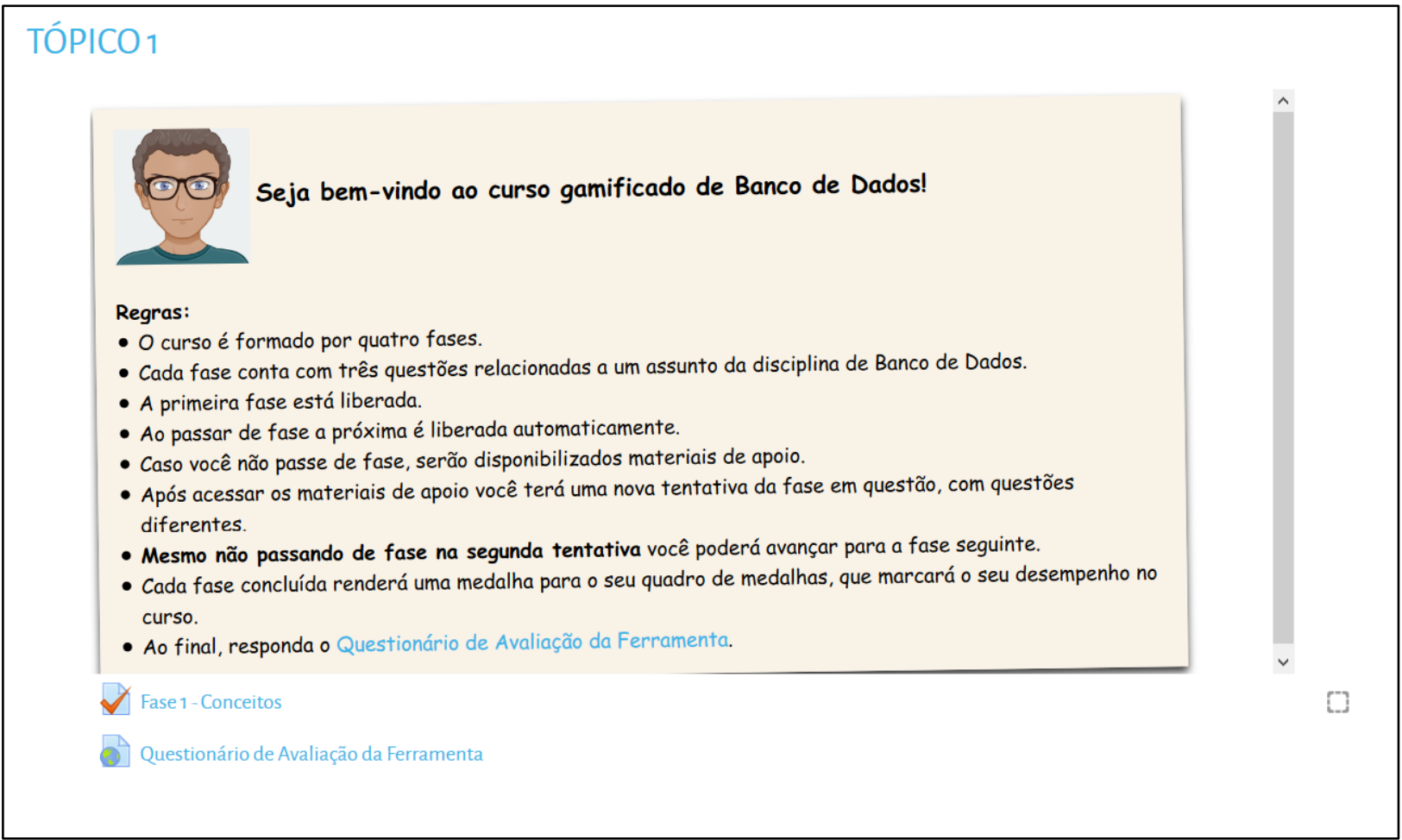

Figura 3: Visão inicial do estudante. Fonte: autor.

Para a construção do mecanismo interativo de tarefas sequenciais foi utilizado o recurso de configuração de restrição de acesso do Moodle. Com ele, é possível adicionar tarefas que só serão acessíveis mediante a satisfação de determinado requisito, como a conclusão de uma atividade anterior, por exemplo. Dessa forma, o sistema exige que o estudante termine a primeira tarefa para acessar a segunda e assim sucessivamente. Esse recurso permitiu a construção da ferramenta de acordo com a modelagem apresentada na Figura 2, por meio da habilitação dinâmica de conteúdos.

Cada fase corresponde a um questionário contendo três questões com nível de dificuldade crescente: fácil, médio e difícil. As duas primeiras valem 3 pontos e a última 4 pontos, totalizando 10. Para ser aprovado, e assim passar de fase, ficou estabelecido que o estudante deve atingir 7 pontos. A ideia com isso foi garantir o acerto na última questão (mais 
difícil) como pré-requisito para avançar para a próxima etapa. Considerando Banco de Dados como temática geral, as fases foram distribuídas em assuntos levando em conta também o aumento gradativo do nível de dificuldade, conforme segue:

- Fase 1: Conceitos.

- Fase 2: Modelagem Entidade Relacionamento.

- Fase 3: SQL.

- Fase 4: JOINS.

Em caso de aprovação, ao atingir os 7 pontos mínimos exigidos para passar de fase, o estudante recebe um feedback do avatar indicando que a próxima fase foi liberada e é orientado a retornar à pagina principal do curso para receber a recompensa. No local, é habilitado um recurso do Moodle do tipo Rótulo com a frase "Você passou da Fase (x)!", acompanhada da orientação para o estudante clicar na caixa de seleção, a fim de receber a medalha que é oferecida pela conclusão da fase em questão. Um exemplo de rótulo de sucesso é mostrado na Figura 4.

Você passou da Fase 1!

Clique no checkbox para receber sua medalha

Figura 4: Rótulo "Você passou". Fonte: autor.

Nos casos em que não atingiu a pontuação mínima, o estudante é informado pelo avatar que não passou daquela fase e recebe a orientação de retornar à página inicial, na qual são disponibilizados materiais de apoio acerca do conteúdo abordado na fase em questão. Um exemplo de feedback com avatar pode ser visualizado na Figura 5. Os materiais oferecidos podem ser arquivos PDF para leitura, links para páginas web externas ou videoaulas em arquivos próprios, ou hospedadas no Youtube. A abertura do material de apoio - ou de pelo menos um dos materiais, para os casos em que eram dispostos mais do que um - é a condição para a habilitação da segunda tentativa da fase que o estudante não passou. Detectado o acesso a no mínimo um dos conteúdos extras, o questionário referente à fase alternativa é habilitado.

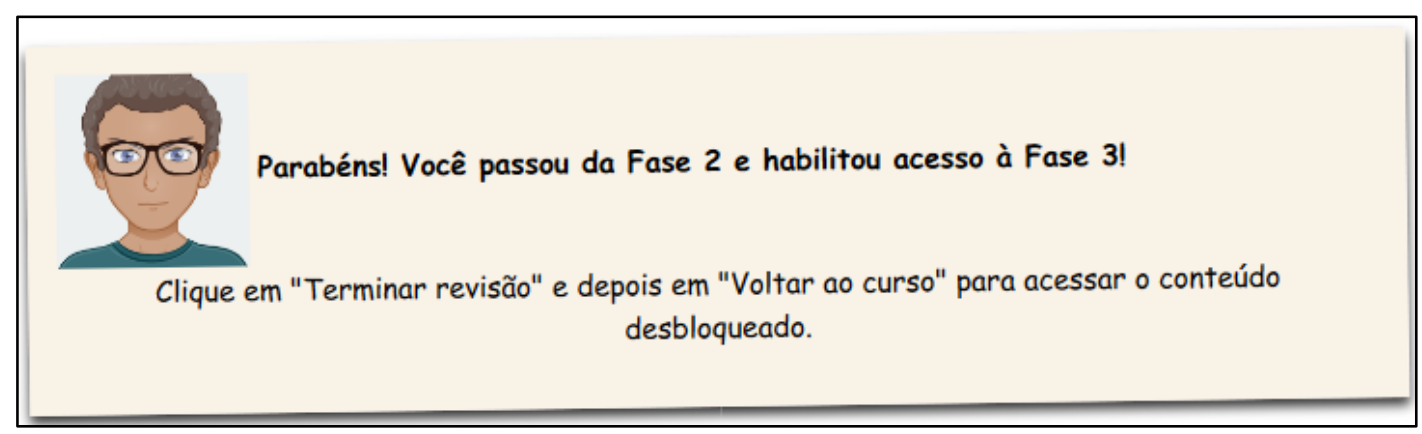

Figura 5: Exemplo de Feedback. Fonte: autor.

As fases alternativas consistem em um novo questionário com o mesmo assunto, número de questões e nível de dificuldade em relação à fase em que o estudante não atingiu a pontuação mínima, contando com perguntas diferentes. As condições para aprovação no questionário alternativo funcionam da mesma forma que nas fases regulares. Se passar de fase, o estudante poderá coletar sua medalha na página inicial e avançar para a próxima etapa; caso contrário, ele é notificado que não passou da fase atual e avança da mesma forma. $\mathrm{O}$ elemento de gamificação Medalha é utilizado aqui para marcar as fases em que o estudante obteve sucesso. Em caso de insucesso na fase alternativa, é apresentado um Rótulo com a frase "Você não passou da Fase (x)!". A disponibilização de materiais didáticos após a não aprovação em uma fase, bem como o rótulo de insucesso são apresentados na Figura 6. 


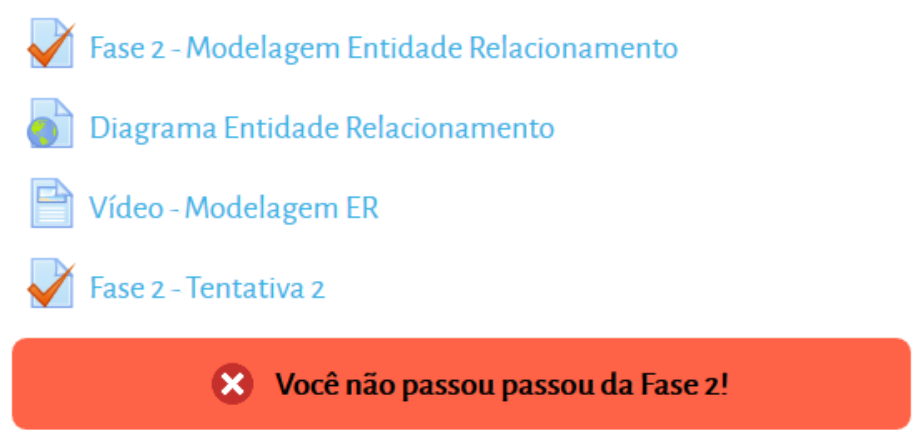

Figura 6: Materiais extras e rótulo de insucesso. Fonte: autor.

As quatro fases funcionam da mesma maneira. Para marcar o final do desafio, a medalha referente à aprovação no último questionário é uma figura diferente do padrão das demais. Da mesma forma, ocorre alteração no rótulo de feedback apresentado caso o estudante seja reprovado na segunda tentativa da última tarefa, passando a apresentar a frase "Game Over", que representa o esgotamento sem aprovação das tentativas. Tais alterações gráficas visam demonstrar ao estudante que a atividade chegou ao fim. A Figura 7 exibe a faixa de insucesso final.

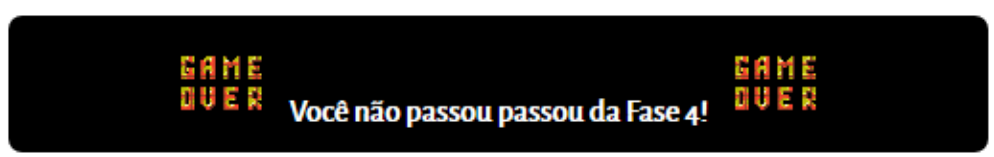

Figura 7: Game Over. Fonte: autor.

Outros elementos de gamificação utilizados foram a Barra de Progresso e Medalhas e Conquistas. O recurso de Emblemas (Badges) é nativo na instalação padrão do Moodle e com ele é possível oferecer uma recompensa em forma de um elemento gráfico na condição que o estudante conclua determinada tarefa. Sempre que consegue passar de fase, independentemente se na primeira ou segunda tentativa, o estudante é premiado com uma medalha no formato de uma imagem que fica posicionada na página do curso, por meio do mecanismo de Emblemas. A medalha correspondente à última fase é destacada com um elemento gráfico diferente para marcar o final da atividade. Para mostrar o progresso do estudante no decorrer das tarefas foi necessária a instalação do plugin Completion Progress ${ }^{1}$, que exibe uma barra com blocos coloridos que referenciam cada um dos recursos didáticos disponíveis no curso. Os recursos concluídos com sucesso são marcados com a cor verde, os recursos em que houve reprovação são marcados com a cor vermelha e os recursos não obrigatórios ou sem avaliação, que não foram acessados ou concluídos, são marcados com a cor azul. Os elementos descritos nesse parágrafo são apresentados na Figura 8.

O último recurso disponibilizado na página do curso é um link para o Questionário de Avaliação da Ferramenta, no qual os estudantes que participaram do estudo de caso tiveram a possibilidade de relatar sua experiência.

\footnotetext{
${ }^{1}$ Plugins são recursos extras disponibilizados pela comunidade de desenvolvedores que trabalham com Moodle com a finalidade de adicionar recursos para a plataforma. O Completion Progress está disponível em: http://moodle.org/plugins/block_completion_progress.
} 

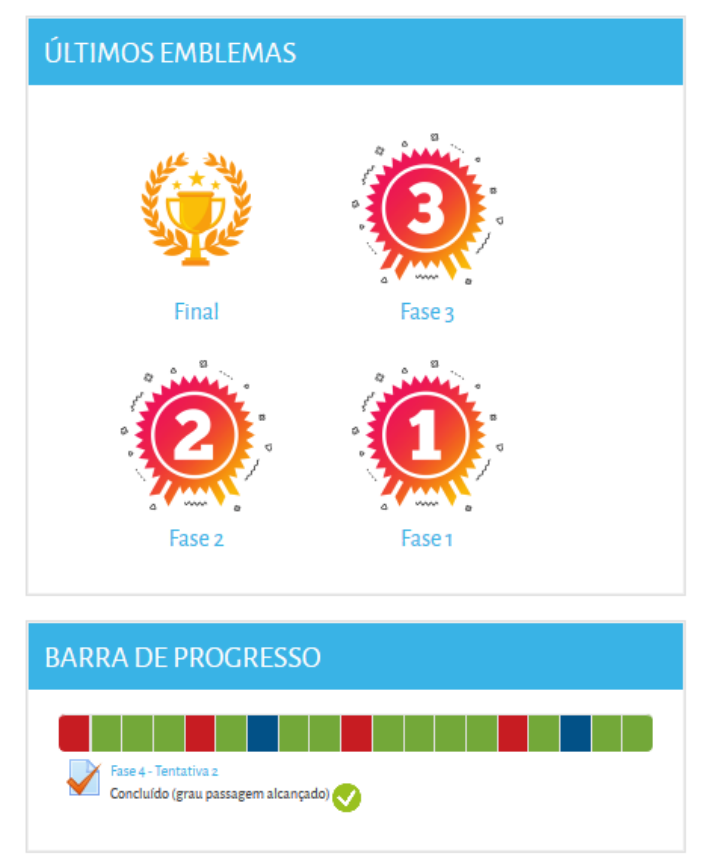

Figura 8: Barra de Progresso e Medalhas. Fonte: autor.

\subsection{Atividade - Grupo Controle}

A atividade disponibilizada para o grupo controle consistiu em um Questionário do Moodle apresentado de forma padrão na página do curso "Banco de Dados", criado para essa finalidade sem a inclusão de técnicas de gamificação ou elementos gráficos. As questões empregadas nesse exercício foram as mesmas encontradas no ambiente gamificado durante as fases regulares, ou seja, aquelas pertencentes às fases alternativas foram descartadas, contabilizando assim 12 questões (três questões por quatro fases).

Para preservar o padrão de comportamento encontrado na atividade do grupo experimental, as questões mantiveram o mesmo peso, ou seja, duas questões valendo 3 pontos e uma valendo 4 pontos a cada grupo de três questões, totalizando o valor de 40 pontos para o questionário com 12 questões. A nota mínima para aprovação foi 28 pontos, correspondente a $70 \%$ da pontuação total.

\section{Resultados}

Nos próximos parágrafos serão apresentados os resultados obtidos com a aplicação do modelo desenvolvido. Para tal levantamento, foi considerada a argumentação proposta por Ferraro (2012) que, em seu artigo, discute as definições clássicas de quantidade e qualidade na pesquisa em educação, nas quais aquela está ligada aos números e às estatísticas e essa toma por base o caráter subjetivo, por meio de narrativas ou documentos pessoais, por exemplo. O autor traz argumentos que classificam a relação entre os métodos qualitativos e quantitativos em três concepções básicas: oposição ou incompatibilidade, complementaridade e unidade. A partir disso, reafirma o entendimento de que não há quantidade sem qualidade, nem vice-versa: a inseparabilidade recíproca entre as duas dimensões é o que garante, segundo o autor, a unidade metodológica necessária para o estudo de determinado problema social ou educacional.

Para a exibição dos resultados no estudo de caso aqui descrito, considerou-se como quantitativo o desempenho dos estudantes nas tarefas e qualitativo a interação dos estudantes com a ferramenta proposta, bem como a análise dos seus impactos como meio facilitador da avaliação para a aprendizagem. A Seção 6.1 tratará do ponto de vista quantitativo, ou seja, a 
identificação do desempenho dos estudantes por meio da ferramenta gamificada em comparação aos que prestaram a atividade normal. A Seção 6.2 abordará a perspectiva qualitativa, na qual serão mensurados os impactos da aplicação do modelo entre os estudantes do grupo experimental.

Quando necessário identificar os estudantes, aqueles pertencentes ao grupo experimental serão chamados de $\boldsymbol{G E n}$, onde n é um número de 1 a 5 e aqueles pertencentes ao grupo controle serão chamados de $\boldsymbol{G C} \mathbf{n}$, onde n é um número de 1 a 6 .

\subsection{Aspecto Quantitativo}

Esta seção é dedicada a identificar os resultados obtidos pelos estudantes do grupo experimental nas fases da ferramenta gamificada, em comparação ao desempenho na atividade do grupo controle.

\subsubsection{Grupo Experimental}

$\mathrm{Na}$ primeira fase, dos cinco estudantes que efetivamente fizeram parte do grupo experimental, apenas um obteve a nota necessária para aprovação, sendo os demais encaminhados para os materiais de apoio. Nessa tarefa, foi disponibilizada uma opção de material extra para liberar a segunda tentativa, portanto os quatro estudantes que não conseguiram passar na primeira tentativa acessaram o documento PDF. A oferta de um caminho extra não se mostrou efetiva e nenhum dos estudantes que tentaram pela segunda vez conseguiu a aprovação tendo, inclusive, dois deles obtido um resultado pior. As notas da primeira fase podem ser visualizadas na Tabela 3.

Tabela 3: Resultado - Fase 1.

\begin{tabular}{|c|c|c|c|}
\hline Estudante & Fase 1 & Fase 1 - Alternativa & Resultado Final \\
\hline GE1 & 10,00 & - & 10,00 \\
\hline GE2 & 3,00 & 3,00 & 3,00 \\
\hline GE3 & 6,00 & 3,00 & 6,00 \\
\hline GE4 & 6,00 & 3,00 & 6,00 \\
\hline GE5 & 6,00 & 6,00 & 6,00 \\
\hline
\end{tabular}

$\mathrm{Na}$ primeira tentativa da segunda tarefa, dois estudantes atingiram o desempenho necessário para avançar e os restantes puderam escolher entre assistir a uma videoaula ou acessar uma página externa com conteúdo de apoio para habilitar a segunda tentativa. A disponibilização do nível extra se mostrou efetiva nesse caso, uma vez que todos os estudantes obtiveram sucesso na fase alternativa. Os resultados são mostrados na Tabela 4.

Tabela 4: Resultado - Fase 2.

\begin{tabular}{|c|c|c|c|}
\hline Estudante & Fase 2 & Fase 2 - Alternativa & Resultado Final \\
\hline GE1 & 6,00 & 7,00 & 7,00 \\
\hline GE2 & 6,00 & 10,00 & 10,00 \\
\hline GE3 & 6,00 & 10,00 & 10,00 \\
\hline GE4 & 10,00 & - & 10,00 \\
\hline GE5 & 7,00 & - & 7,00 \\
\hline
\end{tabular}

O desempenho na Fase 3 manteve a média da tarefa anterior, com dois estudantes obtendo resultado positivo na primeira tentativa. Duas videoaulas foram ofertadas para liberar a fase extra, das quais o estudante precisava acessar ao menos uma para continuar. Na segunda tentativa, um estudante conseguiu atingir a nota máxima enquanto que, dos demais, um obteve um resultado melhor, porém ainda abaixo da nota mínima para aprovação, e o outro manteve desempenho igual. Os resultados da Fase 3 são exibidos na Tabela 5. 
Tabela 5: Resultado - Fase 3.

\begin{tabular}{|c|c|c|c|}
\hline Estudante & Fase 3 & Fase 3 - Alternativa & Resultado Final \\
\hline GE1 & 10,00 & - & 10,00 \\
\hline GE2 & 0,00 & 6,00 & 6,00 \\
\hline GE3 & 6,00 & 6,00 & 6,00 \\
\hline GE4 & 3,00 & 10,00 & 10,00 \\
\hline GE5 & 7,00 & - & 7,00 \\
\hline
\end{tabular}

A última tarefa apresentou um estudante obtendo resultado satisfatório na tentativa inicial. Aqui cabe observar a presença de duas notas 4,00, o que indica acerto na questão considerada difícil combinado com erro nas duas questões anteriores, de nível teoricamente inferior. Para desbloquear a tarefa adicional, foram disponibilizadas duas opções de vídeo das quais o estudante deveria acessar ao menos uma. A última tentativa extra foi exitosa para três dos quatro estudantes que a executaram. As notas da última fase são visualizadas na Tabela 6 .

Tabela 6: Resultado - Fase 4.

\begin{tabular}{|c|c|c|c|}
\hline Estudante & Fase 4 & Fase 4 - Alternativa & Resultado Final \\
\hline GE1 & 7,00 & - & 7,00 \\
\hline GE2 & 4,00 & 4,00 & 4,00 \\
\hline GE3 & 4,00 & 7,00 & 7,00 \\
\hline GE4 & 0,00 & 7,00 & 7,00 \\
\hline GE5 & 6,00 & 7,00 & 7,00 \\
\hline
\end{tabular}

Reunindo os resultados obtidos nas primeiras e segundas tentativas, pode-se afirmar que o estudante GE1 passou da Fase 1, os estudantes GE1, GE2, GE3, GE4 e GE5 passaram da Fase 2, os estudantes GE1, GE4 e GE5 passaram da Fase 3 e os estudantes GE1, GE3, GE4 e GE5 passaram da Fase 4.

A Tabela 7 mostra os desempenhos somados nas quatro tarefas, apresentando as notas obtidas e o percentual em relação ao valor máximo das quatro atividades, de modo a facilitar a comparação com os resultados do grupo controle, sob um peso total de 40 pontos, em que os $70 \%$ necessários para a aprovação correspondem a 28,00. O Resultado Parcial considera o desempenho obtido nas primeiras tentativas, sem a utilização de materiais didáticos ou tentativas extras, e o Resultado Final computa as melhores pontuações que os estudantes alcançaram considerando, nos casos em que houve tentativa extra, o maior valor independentemente se foi obtido na primeira ou segunda tentativa.

Tabela 7: Resultado - Grupo Experimental.

\begin{tabular}{|c|c|c|c|c|}
\hline \multirow{2}{*}{ Estudante } & \multicolumn{2}{|c|}{ Resultado Parcial } & \multicolumn{2}{c|}{ Resultado Final } \\
\cline { 2 - 5 } & Resultado & Aproveitamento & Resultado & Aproveitamento \\
\hline GE1 & 33,00 & $82,5 \%$ & 34,00 & $85 \%$ \\
\hline GE2 & 13,00 & $32,5 \%$ & 23,00 & $57,5 \%$ \\
\hline GE3 & 22,00 & $55 \%$ & 29,00 & $72,5 \%$ \\
\hline GE4 & 19,00 & $47,5 \%$ & 33,00 & $82,5 \%$ \\
\hline GE5 & 26,00 & $65 \%$ & 27,00 & $67,5 \%$ \\
\hline
\end{tabular}

\subsubsection{Grupo Controle}

Para o grupo controle foi disponibilizada uma tarefa que representasse uma atividade avaliativa padrão da disciplina. Portanto, não foram utilizados recursos de gamificação nesse contexto. Para garantir o equilíbrio em relação às atividades prestadas pelo grupo experimental, foi criado um questionário somando as 12 questões das fases regulares - primeiras tentativas - do modelo gamificado. As questões de tentativas extras não foram consideradas. A nota máxima para esse 
questionário é de 40 pontos, com 28 pontos, correspondendo a 70\% do total, o valor mínimo necessário para a aprovação.

$\mathrm{Na}$ atividade proposta para o grupo controle, dos seis participantes, um obteve a nota máxima. Dentre os demais participantes, nenhum atingiu a pontuação mínima para a aprovação, sendo de $60 \%$ o melhor aproveitamento encontrado, descontado o estudante que acertou todas as questões. $\mathrm{O}$ resultado do grupo controle é apresentado na Tabela 8.

Tabela 8: Resultado - Grupo Controle.

\begin{tabular}{|c|c|c|}
\hline Estudante & Resultado & Aproveitamento \\
\hline GC1 & 9,00 & $22,5 \%$ \\
\hline GC2 & 40,00 & $100 \%$ \\
\hline GC3 & 19,00 & $47,5 \%$ \\
\hline GC4 & 24,00 & $60 \%$ \\
\hline GC5 & 22,00 & $55 \%$ \\
\hline GC6 & 19,00 & $47,5 \%$ \\
\hline
\end{tabular}

\subsection{Aspecto Qualitativo}

Esta seção é dedicada a mensurar o impacto que a aplicação da ferramenta gamificada ofereceu na avaliação para a aprendizagem dos estudantes sendo, portanto, considerado exclusivamente o grupo experimental.

Segundo Bogdan e Biklen (1994), a investigação qualitativa preconiza a utilização de múltiplos métodos de coleta de dados de forma interativa. Para tal, no primeiro momento será analisada a interação dos estudantes com a ferramenta de modo a inferir o aproveitamento das potencialidades oferecidas e sua influência no desempenho. Essa análise foi obtida com os Relatórios Completos de Atividade disponibilizados na ferramenta Moodle. Além disso, os cinco estudantes foram convocados a responder um questionário criado com a ferramenta de Formulários do Google após participarem do estudo de caso, por meio de um link disponibilizado abaixo das tarefas na página principal do ambiente.

\subsubsection{Primeiras Afirmações Sobre o Desempenho dos Estudantes}

O estudante GE1 passou pelas Fases 1, 3 e 4 na primeira tentativa, o que leva a inferir que possuía conhecimento prévio sobre o assunto abordado. Quando necessitou utilizar os níveis de interação, na Fase 2, ele escolheu acessar a página web com material de apoio ao invés da videoaula. $\mathrm{O}$ relatório aponta que o estudante levou dois minutos entre o acesso ao conteúdo extra e a segunda tentativa, na qual obteve sucesso. O tempo empregado no material permite concluir que foi realizada uma leitura de consulta.

Por sua vez, o estudante GE2 utilizou tentativas extras em todas as tarefas, obtendo condição de aprovação na Fase 2. Os intervalos de tempo apresentados no relatório apontam que o estudante dedicou três minutos no material extra da primeira fase, acessou as duas opções de material da segunda fase, dedicando dois minutos para estas. Na terceira fase, também acessou as duas alternativas de material, dedicando um tempo de três minutos e, por fím, no último nível o estudante assistiu aos dois vídeos disponibilizados, levando um total de um minuto de interação. O tempo de visualização comparado à duração dos vídeos, ao menos na última fase, indica que o estudante acessou os materiais somente para liberar a nova tentativa. $O$ tempo dedicado para as atividades e materiais didáticos foi diminuindo gradativamente de acordo com o decorrer das fases - o estudante passou um minuto na Fase 4 entre a primeira tentativa, acesso às videoaulas e segunda tentativa. Esse comportamento sugere um descontentamento com o nível de dificuldade das questões propostas ou falta de domínio do conteúdo. 
Utilizando os recursos didáticos em todas as tarefas, o estudante GE3 obteve aprovação nas Fases 2 e 4. Ele dedicou dois minutos para os materiais extras das Fases 1 e 4 e três minutos no caso das Fases 2 e 3 . É possível inferir que os conteúdos foram utilizados para consulta.

O estudante GE4 obteve sucesso nas Fases de 2 a 4, conseguindo a aprovação na primeira tentativa na Fase 2. O estudante despendeu sete minutos para o conteúdo oferecido na Fase 1, três minutos para as videoaulas da Fase 3 e um minuto para o conteúdo da Fase 4 . Aqui a diferença de permanência entre os materiais traz a ideia de que a dedicação foi direcionada de acordo com a familiaridade do estudante com cada um dos temas abordados.

Por fim, o estudante GE5 não conseguiu êxito na primeira fase sendo aprovado nas demais, com sucesso na primeira tentativa nas Fases 2 e 3 . O estudante acessou o material didático da Fase 1 por um minuto, não conseguindo a aprovação na segunda tentativa. Por outro lado, na Fase 4, ele dedicou quatro minutos para assistir às videoaulas da temática de JOINS alcançado, em seguida, a aprovação.

A Tabela 9 apresenta a utilização de tentativas extras pelos estudantes, bem como o tempo médio de acesso aos materiais didáticos de apoio.

Tabela 9: Interação com a ferramenta.

\begin{tabular}{|c|c|c|}
\hline Estudante & Utilização de Tentativa Extra & Média de Acesso \\
\hline GE1 & Fase 2 & 2 minutos \\
\hline GE2 & Fase 1, Fase 2, Fase 3 e Fase 4 & $2: 15$ minutos \\
\hline GE3 & Fase 1, Fase 2, Fase 3 e Fase 4 & $2: 30$ minutos \\
\hline GE4 & Fase 1, Fase 3 e Fase 4 & $3: 40$ minutos \\
\hline GE5 & Fase 1 e Fase 4 & $2: 30$ minutos \\
\hline
\end{tabular}

Os dados disponibilizados pelos relatórios do Moodle permitem analisar a interferência da dinâmica prevista para o estudo de caso no comportamento dos estudantes, assim como observar o tempo das suas interações (Rohling, 2014). Há uma tendência dos estudantes preferirem materiais audiovisuais em detrimento dos arquivos de texto e gráficos. Por outro lado, a diminuição gradativa do tempo de contato com as tarefas e níveis de interação, observada nos dados de determinados estudantes, pode significar o desestímulo sentido em decorrência do nível de dificuldade ou da falta de conhecimento prévio sobre o assunto abordado na atividade.

\subsubsection{Avaliação da Ferramenta}

A Tabela 10 apresenta as questões do Formulário de Avaliação da Ferramenta.

Tabela 10: Formulário de Avaliação da Ferramenta.

\begin{tabular}{|c|l|}
\hline Número & \multicolumn{1}{c|}{ Questão } \\
\hline Q1 & $\begin{array}{l}\text { Considera que os níveis de interação e recursos adicionais (tentativas alternativas e materiais extras) } \\
\text { auxiliam no processo de aprendizagem? }\end{array}$ \\
\hline Q2 & Considera a quantidade de níveis de interação (materiais teóricos adicionais) adequado? \\
\hline Q3 & Considera a quantidade de níveis de interação (tentativas extras) adequada? \\
\hline Q4 & Considera o nível do conteúdo - apenas o material teórico - adequado? \\
\hline Q5 & Considera o nível das questões adequado? \\
\hline Q6 & Considera que a ferramenta atende a necessidade como método de avaliação? \\
\hline Q7 & $\begin{array}{l}\text { Considera que a presença dos elementos de gamificação - medalhas, faixas, regras, estrutura } \\
\text { sequencial gradativa (fases), etc. - contribui para a aprendizagem? }\end{array}$ \\
\hline Q8 & Considera que a experiência com a ferramenta foi divertida? \\
\hline Q9 & $\begin{array}{l}\text { Quanto à experiência de prestar uma tarefa avaliativa em um ambiente gamificado, comparada ao } \\
\text { modelo tradicional (provas, trabalhos) considera o modelo gamificado: Melhor, Pior ou Indiferente. }\end{array}$ \\
\hline Q10 & Aponte aspectos positivos sobre a ferramenta. \\
\hline Q11 & Aponte aspectos negativos sobre a ferramenta. \\
\hline
\end{tabular}


Para as questões de 1 a 8 foi utilizada a escala Likert, um tipo de escala de resposta utilizada em questionários de opinião para especificar o nível de concordância com determinada afirmação (Likert, 1932). O conjunto mais aceito de repostas em uma escala Likert e que foi utilizado no formulário deste projeto é o seguinte: 1. Discordo totalmente, 2. Discordo parcialmente, 3. Indiferente, 4. Concordo parcialmente, 5. Concordo totalmente. Foi desenvolvida em um relatório elaborado pelo psicólogo estadunidense Rensis Likert (Likert, 1932; Macedo, 2020). A nona questão foi do tipo múltipla escolha e as duas últimas foram em formato de texto. A Figura 9 presenta o gráfico das respostas das Questões 1 a 8 , formuladas com a escala Likert.

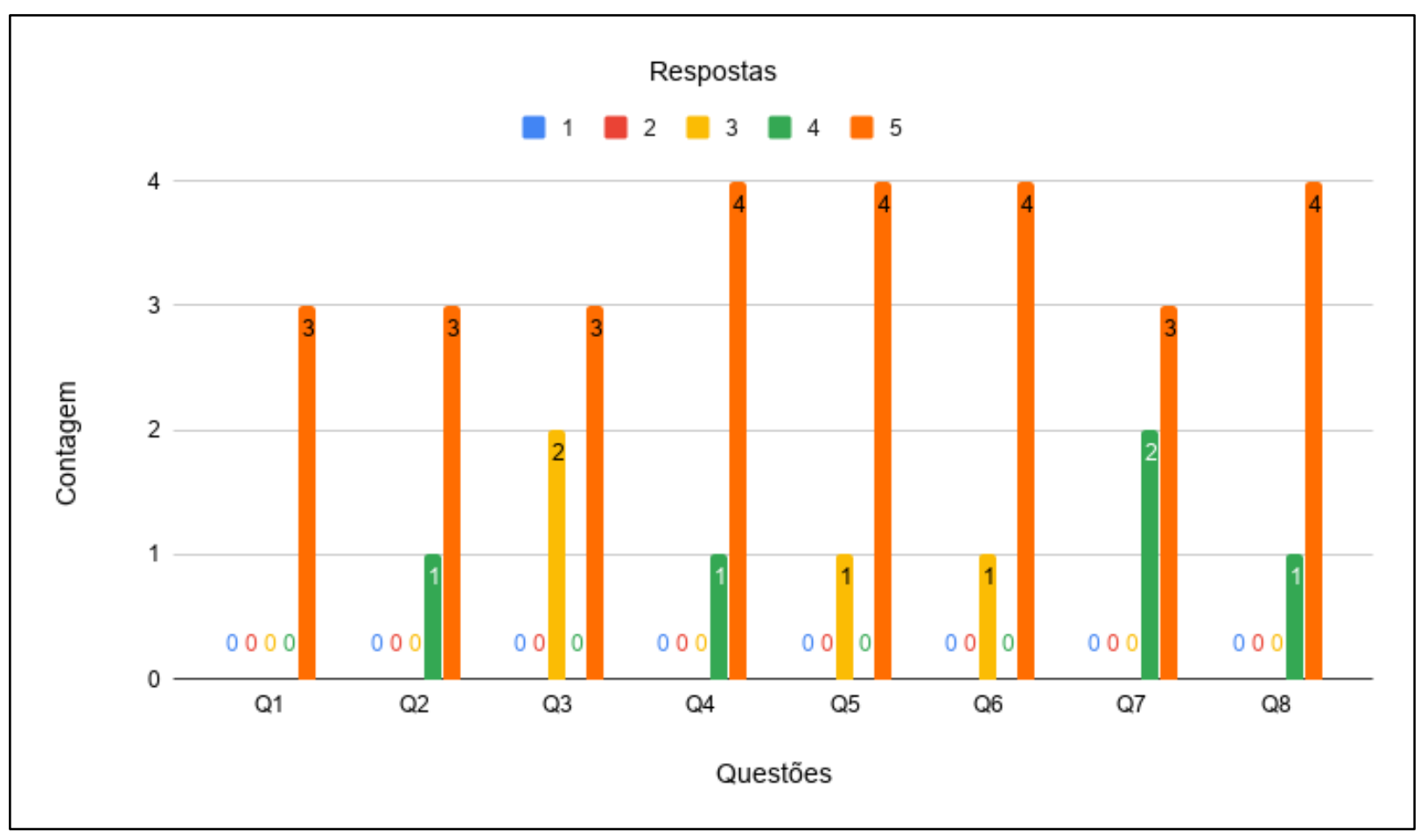

Figura 9: Gráfico - Respostas das Questões de 1 a 8 do Formulário de Avaliação.

O estudo de Souza e Kerbauy (2017) categoriza a abordagem mista da pesquisa quantiqualitativa, na qual, no desenho metodológico exploratório, os resultados qualitativos devem contribuir para o desenvolvimento dos métodos quantitativos. Na mesma linha, as investigações qualitativas devem evitar os enviesamentos e permitir aos participantes relatarem sua experiência de maneira livre (Bogdan e Biklen, 1994). O uso da escala Likert com 5 pontos é considerado o ideal desde a sua criação (Likert, 1932), sendo demonstrada sua adequação para a análise qualitativa de resultados (Macedo, 2020).

Todas as questões de escala Likert obtiveram a maioria de respostas de nível 5 ("concordo totalmente"), o que demonstra que as técnicas empregadas obtiveram aceitabilidade pela maioria dos estudantes. Foram encontradas respostas de nível 4 ("concordo parcialmente") nas questões que perguntavam sobre a quantidade de níveis de interação e nível de dificuldade do conteúdo abordado. O mesmo tipo de resposta foi encontrado na questão que avaliava se o uso de elementos de gamificação contribui para a aprendizagem e se a utilização da ferramenta foi divertida. Ainda que se possa considerar uma concordância no geral, esses pontos merecem atenção caso ocorra a aplicação de estudos semelhantes no futuro.

A Questão 3, que perguntava sobre a quantidade de tentativas extras, foi a que registrou a maior controvérsia, com 2 votos neutros (nível 3, "indiferente") e 3 concordâncias totais. Os itens que investigavam a opinião dos estudantes sobre o nível de dificuldade das questões e se a ferramenta era adequada como instrumento avaliativo obtiveram uma resposta, cada um, de 
nível 3 ("indiferente") e 4 concordâncias totais. Não houve registro de discordância, seja total ou parcial, em nenhuma das questões de escala Likert.

Em relação à Questão 9, na comparação com o modelo tradicional de avaliação, quatro estudantes consideraram a experiência gamificada melhor, enquanto um julgou como indiferente. A opção "Pior" não recebeu votos. As respostas obtidas permitem concluir que a utilização do modelo foi considerada positiva de acordo com a maioria das opiniões coletadas, ainda que existam registros de pontos de insatisfação.

Os dois últimos itens do formulário eram facultativos e consistiam em campos de texto para os estudantes apontarem aspectos positivos ou negativos a respeito da experiência com a ferramenta. Quatro deles apontaram pontos positivos e um apontou ponto negativo. Quanto aos aspectos positivos, as respostas foram as seguintes:

- "Ferramenta muito interativa. Oferece uma melhoria gigantesca em relação ao modelo de avaliações atual."

- "Tem um visual muito superior ao Moodle tradicional (isso é um plus $d+$ (sic), até dá ânimo de abrir o site, diferente do Moodle normal)."

- "Achei muito legal oferecer material de apoio após um erro."

- "É uma maneira muito boa, divertida e diferente. Uma ferramenta que se eu tivesse acesso utilizaria com muito prazer."

Em oposição, a resposta sobre aspecto negativo recebida foi:

- “Com apenas 3 questões não dá para definir se a pessoa sabe ou não determinado assunto, logo, seria interessante englobar mais questões abordando o assunto, com um nível de dificuldade um pouco inferior."

As declarações registradas vão ao encontro das questões anteriores, em que o modelo é considerado positivo pelos estudantes. O pequeno número de questões é justificado pelo fato do modelo ter sido idealizado para aplicação em um período de aula. A ideia do estudo de caso não foi definir se o estudante sabe ou não, mas oferecer uma ferramenta para analisar a o impacto do uso da gamificação voltada à avaliação para a aprendizagem, na sua perspectiva formativa. Nesse sentido, fica evidenciado o aspecto subjetivo da avaliação, em que a mesma não deve ser centrada totalmente nas notas (Cunha, 1999), mas levar em conta as relações dinâmicas que inerentes ao processo avaliativo (Casanova et al., 2017; Kenski, 1994), o que justifica a análise das interações dos estudantes e a coleta de informações.

\section{Considerações Finais}

O artigo teve como objetivo apresentar um modelo de avaliação para a aprendizagem integrando gamificação e teoria sobre avaliação formativa que atendesse aos problemas encontrados na literatura no trato da avaliação em experiências gamificadas. Dessa forma, primeiramente foram apresentados os aspectos teóricos que fundamentaram a pesquisa. Com base nas ideias depreendidas, foi proposto o modelo de avaliação com gamificação e, em seguida, descrita a sua aplicação a uma turma voluntários, estudantes de Engenharia de Computação da FURG.

O grupo de estudantes foi dividido em dois, de acordo com os critérios objetivos baseados no SISU. Para um dos grupos foi proposta uma tarefa avaliativa com gamificação, enquanto que para o restante foi disponibilizado um questionário simples. Em seguida, foram catalogados os desempenhos dos estudantes, em cada um dos ambientes, para promover a avaliação quantitativa da aplicação do modelo gamificado. Os dados dos relatórios de atividade, bem como as respostas dos estudantes em um formulário de avaliação da ferramenta, foram 
coletados para mensurar o impacto do emprego da gamificação voltada para avaliação formativa de estudantes de engenharia, em seu aspecto qualitativo.

Em relação ao progresso dos estudantes na atividade do grupo experimental, que utilizou técnicas de gamificação, percebe-se que dois deles passaram pelas quatro fases obtendo, portanto, o aproveitamento de $100 \%$. Um passou por três fases obtendo o aproveitamento de $75 \%$, um passou por duas fases obtendo o aproveitamento de $50 \%$ e um passou por uma fase obtendo o aproveitamento de $25 \%$. Se o total das notas for considerado, para efeitos de comparação, conforme pode ser visualizado nas Tabelas 7 e 8, respectivamente, é possível notar que o grupo experimental obteve melhor resultado já que três dos cinco estudantes alcançaram notas iguais ou superiores a 28,00, que correspondem aos $70 \%$ do total necessários para a aprovação. Cabe a ressalva de que dos restantes, um fez 27,00 pontos, correspondendo a $67,5 \%$. Por outro lado, o grupo controle teve como atividade um questionário com valor total de 40,00 pontos em que um dos estudantes acertou todas as questões enquanto que, dos restantes, o aproveitamento máximo alcançado foi de $60 \%$.

Para o caso em questão, é possível afirmar que o emprego das técnicas de gamificação promoveu a obtenção de melhor desempenho e teve recepção positiva, bem como a disponibilização de materiais de apoio e tentativas extras foi capaz de impulsionar os resultados dos estudantes, no que ser refere à avaliação para a aprendizagem. Conforme os dados apresentados na Tabela 7, todos os estudantes que utilizaram recursos de gamificação obtiveram melhor resultado em comparação com o seu desempenho inicial. Em compensação, cabe a ressalva de que o estudante com melhor desempenho individual pertence ao grupo controle. Em termos de notas, o desempenho médio dos estudantes do grupo experimental foi de $60,83 \%$ enquanto que do grupo controle foi de $55,42 \%$.

A opinião dos estudantes coletada por meio do Formulário da Avaliação da Ferramenta permite apontar que a aplicação do modelo com técnicas de gamificação foi considerada positiva. Todos os estudantes que utilizaram níveis de interação concordam que os mesmos auxiliam no processo de aprendizagem, bem como que o número de itens e o nível do conteúdo de material teórico foi adequado. Em relação à presença dos itens de gamificação como facilitadores da aprendizagem e à avaliação se a ferramenta foi considerada divertida também houve concordância: $80 \%$ dos estudantes avaliam que o modelo gamificado é melhor do que o tradicional, $20 \%$ consideram indiferente e nenhum deles entende que o modelo é pior. Em compensação, a ocorrência de respostas neutras nas questões que avaliavam a quantidade dos níveis de interação em relação às tentativas extras, o grau de dificuldade das questões e se a ferramenta em si atendia as necessidades de uma atividade avaliativa demonstram pontos a ser mais bem investigados. Os aspectos positivos apontados foram a interatividade, o visual da ferramenta, a disponibilização de material de apoio após um erro e o fato da utilização ser divertida. Como ponto negativo que precisa de maior atenção, foi assinalada a pequena quantidade de questões, fator que pode prejudicar a avaliação. A quantidade de questões pode ser justificada pelo fato do modelo ter sido projetado para ser empregado com a limitação de tempo de uma aula. Considerando os dados apresentados na Seção 6.2.1, no que se refere aos conteúdos disponibilizados, nota-se que materiais do tipo vídeo são mais atrativos em comparação aos textos, podendo-se inferir que os estudantes preferem ver ou escutar um conteúdo a ler.

Analisando a aceitação do modelo, compreende-se que os estudantes de engenharia se sentiram contemplados pela utilização da ferramenta gamificada como modelo de avaliação. Nas condições em que o estudo de caso foi realizado, é possível concluir que as técnicas de gamificação promovem ganho de desempenho e são consideradas positivas pelos estudantes. 


\subsection{Trabalhos Futuros}

Como continuidade do estudo apresentado neste artigo, vislumbram-se propostas de melhorias no modelo de avaliação. A primeira delas seria a utilização de uma ferramenta semelhante com mais voluntários em um período de tempo maior contando, também, com um maior número de questões de modo que a nota para aprovação em cada fase seja diluída, bem como com mais níveis de interação e que os materiais teóricos disponibilizados a cada etapa também sejam incrementados. Entende-se que dessa forma a avaliação do impacto da gamificação para avaliar o aprendizado de estudantes de engenharia seja mais adequada.

No estudo de caso descrito foi apresentado um conjunto fixo de perguntas, desse modo, para próximas implementações, a ideia é a criação de um banco de questões que sejam sorteadas via sistema e apresentadas uma por vez, randomicamente. Assim sendo, a dinâmica poderia ser alterada para prever um número mínimo de questões a serem respondidas como pré-requisito em cada fase - no caso do estudo aqui descrito seriam seis (três na primeira tentativa e três na segunda) - e disponibilizar os materiais de auxílio dinamicamente a cada ocorrência de erro para ao final somar a pontuação e classificar se o desempenho do estudante foi satisfatório para passar de fase ou não.

A pesquisa pode ser ampliada se a ferramenta for empregada em diversos contextos, sem a necessidade de o professor ter o conhecimento técnico sobre tecnologia da informação. Para isso, pode ser criado um framework para que os docentes informem o número total de questões e as incluam no sistema que fará a construção dinâmica da ferramenta gamificada. Espera-se com isso poder aplicar o modelo proposto em diferentes áreas do conhecimento, bem como sanar um dos problemas apontados no estudo de caso, que foi a baixa quantidade de questões.

\section{Referências}

Abreu, M. C., \& Masetto, M. T. (1989). O Professor Universitário Em Aula. São Paulo: MG Associados. [GS Search]

Araújo, F., \& Diniz, J. (2015). Hoje, de que falamos quando falamos de avaliação formativa? Boletim Da Sociedade Portuguesa de Educação Física, (39), 41-52. [GS Search]

Attali, Y., \& Arieli-Attali, M. (2015). Gamification in assessment: Do points affect test performance? Computers and Education, 83, 57-63. doi: 10.1016/j.compedu.2014.12.012 [GS Search]

Ávila, C. L., \& Gómez, S. B. (2017). La gamificación en la educación superior: una revisión sistemática. Revista Ingenierías Universidad de Medellín, 16(31), 97-124. doi: 10.22395/rium.v16n31a5 [GS Search]

Barata, G., Gama, S., Jorge, J., \& Goncalves, D. (2013). Engaging engeneering students with gamification. 2013 5th International Conference on Games and Virtual Worlds for Serious Applications, VS-GAMES 2013. doi: 10.1109/VS-GAMES.2013.6624228 [GS Search]

Bissolotti, K., Nogueira, H. G., \& Pereira, A. T. C. (2014). Potencialidades das mídias sociais e da gamificação na educação a distância. RENOTE - Revista Novas Tecnologias Na Educação - CINTED/UFRGS, 12(2). doi: 10.22456/1679-1916.53511 [GS Search]

Boaventura, E. F., \& Oliveira, R. de C. S. (2018). Gamificação: Uma Análise De Sua Aplicação Como Ferramenta De Engajamento, Aprendizagem E Interação Em Ambientes Virtuais. RBEC - Revista Brasileira de Educação e Cultura, 17, 104-128. [GS Search]

Bogdan, R., \& Biklen, S. (1994). Investigação qualitativa em educação: uma introdução à teoria e aos métodos. Porto: Porto Editora. [GS Search] 
Bordernave, J. D. (1977). Estratégias de ensino-aprendizagem. Petrópolis: Vozes. [GS Search]

Brazil, A., \& Baruque, L. (2015). Gamificação Aplicada na Graduação em Jogos Digitais. Anais Do XXVI Simpósio Brasileiro de Informática Na Educação (SBIE 2015), 1(Sbie), 677-686. doi: $\underline{10.5753 / \mathrm{cbie} . s b i e .2015 .677 \text { [GS Search] }}$

Casanova, P., Rocha, A. P., Amante, L., \& Oliveira, I. (2017). A avaliação formativa digital. Projeto de intervenção numa escola. Challenges 2017 Aprender Nas Nuvens, Learning in the Clouds, (X), 1821-1833. Disponível em: http://hdl.handle.net/1822/54072 [GS Search]

Cavalcante, A. A., Sales, G. L., \& Silva, J. B. da. (2018). Tecnologias digitais no Ensino de Física: um relato de experiência utilizando o Kahoot como ferramenta de avaliação gamificada. Research, Society and Development, 7(11), 01-17, e7711456. doi: $\underline{10.17648 / \mathrm{rsd}-\mathrm{v} 7 \mathrm{i} 11.456}$ [GS Search]

Cunha, M. I. da. (1999). A avaliação da aprendizagem no ensino superior. Avaliação, 4(4), 713. [GS Search]

Deterding, S., Dixon, D., Khaled, R., \& Nacke, L. (2011). From game design elements to gamefulness: Defining gamification. Proceedings of the 15th International Academic MindTrek Conference on Envisioning Future Media Environments - MindTrek '11, 9-11. doi: $\underline{10.1145 / 2181037.2181040}$ [GS Search]

Dias Sobrinho, J., \& Balzan, N. C. (1995). Avaliação Institucional: Marcos teóricos e políticos. Avaliação, 1(1), 15-24.

Evangelista, T. da S., Tognetti, T. C., Amorim, R. G. G. de, \& S. Neto, A. F. (2018). Math Game: Uma Estratégia Lúdica para o Ensino de Cálculo Diferencial e Integral em Cursos de Engenharia. Revista de Ensino de Engenharia, 37(1), 57-65. doi: 10.5935/2236$\underline{0158.20180006}$ [GS Search]

Fardo, M. L. (2013). A Gamificação Aplicada em Ambientes de Aprendizagem. RENOTE, 11(1), 291-298. doi: 10.22456/1679-1916.41629 [GS Search]

Ferraro, A. R. (2012). Quantidade e qualidade na pesquisa em educação, na perspectiva da dialética marxista. Pro-Posições, 23(1), 129-146. doi: 10.1590/S0103$\underline{73072012000100009}$ [GS Search]

Harlen, W., \& James, M. (1997). Assessment and Learning: differences and relationships between formative and summative assessment. Assessment in Education: Principles, Policy \& Practice, 4(3), 365-379. doi: 10.1080/0969594970040304 [GS Search]

Kapp, K. (2012). The gamification of learning and instruction: game-based methods and strategies for training and education. San Francisco, CA: Pfeiffer. [GS Search]

Kenski, V. M. (1994). Avaliação da aprendizagem. In VEIGA, L. P. A. (coord) et al. Representando a didática. (pp. 131-144). Campinas - SP: Papirus. [GS Search]

Klock, A. C. T., Carvalho, M. F. de, Rosa, B. E. da, \& Gasparini, I. (2014). Análise das técnicas de Gamificação em Ambientes Virtuais de Aprendizagem. RENOTE - Revista Novas Tecnologias Na Educação, 12(2), 1-10. doi: 10.22456/1679-1916.53496 [GS Search]

Lee, J. J., \& Hammer, J. (2011). Gamification in Education: What, How, Why Bother? Academic Exchange Quarterly, 15(2), 1-5. [GS Search]

Likert, R. (1932). A Technique for the Measurement of Attitudes (Archives o). New York: The Science Press. [GS Search]

Luckesi, C. (1998). Avaliação da aprendizagem escolar (8a ed.). São Paulo: Cortez. [GS $\underline{\text { Search }]}$ 
Ludke, M., \& Salles, M. M. Q. P. (1997). Avaliação da aprendizagem na educação superior. In LEITE, Denise B. C., MOROSINI, Marília. (Orgs.) Universidade Futurante - produção do ensino e inovação. Campinas - SP: Papirus. [GS Search]

Luz, A. A. da. (1997). A avaliação no ensino superior. Educar Em Revista, 13(13), 55-66. doi: 10.1590/0104-4060.171 [GS Search]

Macedo, S. B. (2020). Quantos pontos são necessários? Um estudo comparativo de escalas Likert, do tipo Likert e semântica. Revista Horizontes Interdisciplinares Da Gestão, 4(2), 104-119. [GS Search]

Machado, N. J. (1995). Epistemologia e didática, as concepções de conhecimento e inteligência e a prática docente. São Paulo: Cortez.

McGonigal, J. (2012). A Realidade em Jogo: Porque os Games nos Tornam Melhores e Como Eles Podem Mudar o Mundo (BestSeller, ed.). Rio de Janeiro: BestSeller. [GS Search]

Mendes, O. M. (2005). Avaliação formativa no ensino superior: reflexões e alternativas possíveis. Currículo e Avaliação Na Educação Superior, 175-197. [GS Search]

Menezes, C. C. N., \& Bortoli, R. (2016). A Gamificação da Avaliação: Instrumento de Inovação Pedagógica. 7th International Symposium on Technological Innovation, 3, 439-445. Universidade Federal de Sergipe. doi: 10.7198/S2318-3403201600030052 [GS Search]

Ortigão, M. I. R., Fernandes, D., Pereira, T. V., Santos, L., Lopes, A. C., \& Macedo, E. (2019). Avaliar para aprender no Brasil e em Portugal: Perspectivas Teóricas, Práticas e de Desenvolvimento Série Temas em currículo, docência e avaliação - volume 6. In Avaliar para aprender em Portugal e no Brasil: Perspectivas teóricas e de desenvolvimento. EDITORA CRV. doi: 10.24824/978854443463.5 [GS Search]

Piteira, M., Costa, C. J., \& Aparicio, M. (2017). CANOE e Fluxo: Determinantes na adoção de curso de programação online gamificado. RISTI - Revista Iberica de Sistemas $e$ Tecnologias de Informacao, 2017(25), 34-53. doi: 10.17013/risti.25.34-53 [GS Search]

Rohling, N. (2014). A Pesquisa Qualitativa e Análise Dialógica do Discurso: Caminhos Possíveis. 15(3), 44-60. doi: 10.26512/les.v15i2.7561 [GS Search]

Rojas, J. M., \& Fraser, G. (2016). Teaching Mutation Testing using Gamification. European Conference of Software Engineering Education 2016 (ECSEE), 1-5. [GS Search]

Salami, A. D. G., Silva, E. R. da, Tisott, P. B., Dias, D. T. de Á., \& Bocchese, P. (2018). Gamificação: a Proposição de um Modelo para Aplicação nas Empresas. XVIII Mostra de Iniciação Científica, Pós-Graduação, Pesquisa e Extensão, (September 2019), 1-14. Educs. doi: 10.18226/610001/MOSTRAXVIII.2018.29 [GS Search]

Sande, D., \& Sande, D. (2018). Uso Do Kahoot Como Ferramenta De Avaliação E EnsinoAprendizagem No Ensino De Microbiologia Industrial. Holos, 1, 170-179. doi: $\underline{10.15628 / \text { holos.2018.6300 [GS Search] }}$

Santos, C. M. dos, \& Kroeff, R. F. da S. (2018). A contribuição do feedback no processo de avaliação formativa. EDUCA - Revista Multidisciplinar Em Educação, 5(11), 20-39. doi: $\underline{10.26568 / 2359-2087.2018 .2776}$ [GS Search]

Santos, I. T. R. dos, Barreto, D. A. B., \& Soares, C. V. C. de O. (2021). Formative assessment in the classroom: the dialogue between teachers and students. Journal of Research and Knowledge Spreading, 1(1), 11483. doi: 10.20952/jrks1111483 [GS Search]

Santos, J. de A. dos, \& Freitas, A. L. C. de. (2017). Gamificação Aplicada a Educação: Um Mapeamento Sistemático da Literatura. RENOTE, 15(1), 190-196. doi: 10.22456/1679$\underline{1916.75127}$ [GS Search] 
Seaborn, K., \& Fels, D. I. (2015). Gamification in theory and action: A survey. International Journal of Human Computer Studies, 74, 14-31. doi: 10.1016/j.ijhcs.2014.09.006 [GS Search]

Silva, F. C., Carvalho, A. C. S. A., Ligabo, M., Rodrigues Jr, D., \& Rodrigues, R. C. L. B. (2020). Proposta para Implementar Avaliação Formativa no Ensino Médio. Ciência \& Educação (Bauru), 26, 1-17. doi: 10.1590/1516-731320200026 [GS Search]

Silva, J. C., Rodriguez, C., \& Rocha, R. V. da. (2019). Uma metodologia para aplicação de estratégias de gamificação na avaliação da aprendizagem de alunos. Anais Do XXX Simpósio Brasileiro de Informática Na Educação (SBIE 2019), (Cbie), 1002-1011. Brazilian Computer Society (Sociedade Brasileira de Computação - SBC). doi: $\underline{10.5753 / \text { cbie.sbie.2019.1002 [GS Search] }}$

Silva, N. L., \& Mendes, O. M. (2017). Avaliação formativa no ensino superior: avanços e contradições. Avaliação: Revista Da Avaliação Da Educação Superior (Campinas), 22(1), 271-297. doi: 10.1590/s1414-40772017000100014 [GS Search]

Souza, K. R., \& Kerbauy, M. T. M. (2017). Abordagem quanti-qualitativa: superação da dicotoamia quantitativa-qualitativa na pesquisa em educação. Educação e Filosofia, 31(61), 21-44. doi: 10.14393/revedfil.issn.0102-6801.v31n61a2017-01 [GS Search]

Souza, M. R. de A., Veado, L., Moreira, R. T., Figueiredo, E., \& Costa, H. (2018). A systematic mapping study on game-related methods for software engineering education. Information and Software Technology, 95(April 2017), 201-218. doi: 10.1016/j.infsof.2017.09.014 [GS Search]

Tobon, S., Ruiz-Alba, J. L., \& García-Madariaga, J. (2020). Gamification and online consumer decisions: Is the game over? Decision Support Systems, 128(December 2018), 113167113180. doi: 10.1016/j.dss.2019.113167 [GS Search]

Toda, A. M., Valle, P. H. D., Guessi, M., Rocha, R. V. da, Maldonado, J. C., \& Isotani, S. (2017). Plataforma de Recursos Educacionais Abertos: Uma Arquitetura de Referência com Elementos de Gamificação. Renote, 14(2), 1-10. doi: 10.22456/1679-1916.70650 [GS Search]

Tolomei, B. V. (2017). A Gamificação como Estratégia de Engajamento e Motivação na Educação. EAD Em FOCO Revista Cientifica Em Educação a Distância., 7(2), 145-156. doi: $10.18264 /$ eadf.v7i2.440 [GS Search]

Vieira, A. D. S., Saibert, A. P., Neto, M. J. R., Costa, T. M. da, \& Paiva, N. D. S. (2019). O estado da arte das práticas de gamificação no processo de ensino e aprendizagem no ensino superior. Revista Brasileira de Ensino Superior, 4(1), 5-23. doi: 10.18256/24473944.2018.v4i1.2185 [GS Search]

Wünderlich, N. V., Gustafsson, A., Hamari, J., Parvinen, P., \& Haff, A. (2020). The great game of business: Advancing knowledge on gamification in business contexts. Journal of Business Research, 106(November 2019), 273-276. doi: 10.1016/j.jbusres.2019.10.062 [GS Search] 